\title{
Using chitosan microparticles to treat metritis in lactating dairy cows
}

\author{
E. B. de Oliveira, ${ }^{1 *}$ (ㄷ F. Cunha, ${ }^{1} \odot$ R. Daetz, ${ }^{1}$ C. C. Figueiredo, ${ }^{1} \odot$ R. C. Chebel, ${ }^{1} \odot$ J. E. Santos,,${ }^{2,3}$ \\ C. A. Risco, ${ }^{1}$ † K. C. Jeong, ${ }^{2,4} \odot$ V. S. Machado, ${ }^{5} \odot$ and K. N. Galvão ${ }^{1,3} \ddagger \odot$ \\ ${ }_{1}^{1}$ Department of Large Animal Clinical Sciences, University of Florida, Gainesville 32610 \\ ${ }^{2}$ Department of Animal Sciences, University of Florida, Gainesville 32610 \\ ${ }^{3}$ D. H. Barron Reproductive and Perinatal Biology Research Program, University of Florida, Gainesville 32610 \\ ${ }^{4}$ Emerging Pathogens Institute, University of Florida, Gainesville 32610 \\ ${ }^{5}$ Department of Veterinary Sciences, Texas Tech University, Lubbock 79409
}

\section{ABSTRACT}

The main objective of this study was to evaluate the efficacy of intrauterine administration of chitosan microparticles $(\mathrm{CM})$ in curing metritis in dairy cows. A secondary objective was to evaluate the effects of metritis treatments on milk yield, survival, and reproductive performance. Cows with a fetid, watery, red-brownish vaginal discharge were diagnosed with metritis. Holstein cows $(\mathrm{n}=826)$ with metritis from 3 dairies located in northern Florida were blocked by parity (primiparous or multiparous) and, within each block, randomly assigned to one of 3 treatments: CM (n $=276)=$ intrauterine infusion of $24 \mathrm{~g}$ of $\mathrm{CM}$ dissolved in $40 \mathrm{~mL}$ of sterile distilled water at the time of metritis diagnosis (d 0), 2 (d 2), and 4 (d 4) d later; ceftiofur $(\mathrm{CEF} ; \mathrm{n}=275)=$ subcutaneous injection of $6.6 \mathrm{mg} /$ $\mathrm{kg}$ ceftiofur crystalline-free acid in the base of the ear at $\mathrm{d} 0$ and $\mathrm{d} 3$; Control $(\mathrm{CON} ; \mathrm{n}=275)=$ no treatment applied at metritis diagnosis. All groups could receive escape therapy if condition worsened. Cure was considered when vaginal discharge became mucoid and not fetid. A group of nonmetritic (NMET; $\mathrm{n}=2,436$ ) cows was used for comparison. Data were analyzed by generalized linear mixed and Cox's proportional hazard models. Cows in CM and CON had lesser risk of metritis cure on d 12 than cows in CEF (58.6 \pm 5.0 vs. $61.9 \pm 4.9 \%$ vs. $77.9 \pm 3.9$, respectively). The proportion of cows culled within 60 days in milk (DIM) was greater for cows in $\mathrm{CM}$ than for cows in $\mathrm{CEF}$ and $\mathrm{CON}$ $(21.5 \pm 2.7$ vs. $9.7 \pm 1.9$ vs. $11.3 \pm 2.0 \%$, respectively $)$. Treatment did not affect rectal temperature or plasma

Received December 9, 2019

Accepted March 16, 2020.

*Current address: Veterinary Medicine Teaching and Research Center, University of California, Davis, Tulare, CA 93274.

†Current address: The Center for Veterinary Health Sciences, Oklahoma State University, Stillwater, OK 74078.

$\ddagger$ Corresponding author: galvaok@ufl.edu nonesterified fatty acids, $\beta$-hydroxybutyrate, and haptoglobin concentrations. Milk yield in the first 60 DIM differed for all treatments, and it was lowest for CM $(35.8 \pm 0.3 \mathrm{~kg} / \mathrm{d})$, followed by CON $(36.8 \pm 0.3 \mathrm{~kg} / \mathrm{d})$ and CEF $(37.9 \pm 0.3 \mathrm{~kg} / \mathrm{d})$. The hazard of pregnancy up to 300 DIM was lesser for CM than CEF (hazard ratio $=0.62 ; 95 \%$ CI: $0.50-0.76)$, for $\mathrm{CM}$ than $\mathrm{CON}$ (hazard ratio $=0.77 ; 95 \%$ CI: $0.62-0.95)$ and for CON than CEF (hazard ratio $=0.80 ; 95 \%$ CI: 0.65-0.99). Culling was greater, and milk yield and fertility were lesser for CEF than NMET. In summary, CM did not improve the cure of metritis, and was detrimental to milk yield, survival, and fertility compared with CON. In contrast, $\mathrm{CEF}$ increased the cure of metritis, milk yield, and fertility compared with CM and CON. Finally, the negative effects of metritis on milk yield culling and fertility could not be completely reversed by CEF. Key words: metritis, chitosan microparticle, ceftiofur, dairy cow

\section{INTRODUCTION}

Metritis, an acute inflammatory disease of multiple layers of the uterine lining, affects 20 to $40 \%$ of postpartum dairy cows in the first 21 DIM (LeBlanc et al., 2002; Sheldon et al., 2009; Dubuc et al., 2010). In cows with risk factors such as dystocia, delivery of twin calves, retained fetal membranes (RFM), or stillbirth, the incidence of metritis ranges from 30 to 45\% (Markusfeld, 1987; Bell and Roberts, 2007; Benzaquen et al., 2007). The consequences of metritis include reduced welfare (Stojkov et al., 2015), increased incidence of other diseases, decreased productive and reproductive performance, increased culling, and decreased profitability (Erb and Martin, 1980; Kossaibati and Esslemont, 1997; Sheldon and Dobson, 2004).

The dairy cow is unique in that virtually all cows are contaminated with bacteria in the first days following calving (Sheldon and Dobson, 2004; Jeon et al., 2015); however, cows with risk factors for metritis 
are more likely to have pathogenic bacteria than cows without risk factors (Bicalho et al., 2010; Giuliodori et al., 2013). Failure to eliminate pathogenic bacteria leads to the establishment of disease. A broad-spectrum third-generation cephalosporin, namely ceftiofur, is the antibiotic of choice for treating metritis, primarily because it does not require milk withdrawal. The Food and Drug Administration (FDA), citing concerns for human health because of development of antibiotic resistance, has banned the use of third-generation cephalosporins for disease prevention in cattle, swine, chickens, and turkeys. If this action is not enough to control antibiotic resistance, the next step might be to ban its use for disease treatment, as is the case in the Netherlands (De Briyne et al., 2014). This highlights the need for alternatives to traditional antibiotics for prevention and treatment of diseases in food animals. Chitosan, which is categorized as generally recognized as safe (GRAS) by the FDA, is made out of chitin. Chitin is the second most abundant biopolymer on earth after cellulose. It is part of the structural components of the exoskeleton of arthropods and the cell walls of fungi and yeast. Chitosan is a linear polysaccharide produced by deacetylation of chitin and is nontoxic, bioadhesive, biocompatible, and biodegradable (Baldrick, 2010). Because of these desirable characteristics, chitosan has been used broadly in the food, pharmaceutical, textile, agriculture, and cosmetics industries, as well as for water treatment (Baldrick, 2010). Chitosan microparticles (CM) have broad-spectrum antimicrobial activity at acidic and neutral pH (Jeon et al., 2014). Therefore, CM seems to be a promising alternative to traditional antibiotics for the treatment of disease in dairy cows. More specifically, the $\mathrm{pH}$ of uterine discharge from cows with metritis was $6.84 \pm 0.02$, whereas the $\mathrm{pH}$ from cows without metritis was $6.97 \pm 0.03$ from 4 to 14 DIM (Daetz et al., 2016).

In this study, CM was evaluated as an alternative treatment for metritis. The rationale for this study was that development of an effective alternative to current antibiotic treatments could improve animal health, welfare, and fertility, which would enhance farm profitability and sustainability. Furthermore, reducing dependence on traditional antibiotics is expected to delay development of bacterial resistance to antibiotics used in human medicine such as third-generation cephalosporins, improving public sentiment toward animal agriculture, and the sustainability of the dairy industry.

We hypothesized that cure of metritis with CM treatment would be similar to treatment with ceftiofur $(\mathbf{C E F})$, and both treatments would be superior to the control (CON). In addition, we hypothesized that blood analytes (i.e., nonesterified fatty acids, NEFA;
BHB; and haptoglobin, $\mathbf{H p}$ ) and rectal temperature would decrease at a faster rate in CM and CEF treated cows than in CON cows. Finally, we hypothesized that an effective treatment for metritis would have positive effects on milk yield, reproductive performance, and survival of dairy cows. The objective of this experiment was to evaluate the efficacy of intrauterine administration of CM for the treatment of metritis in dairy cows, and a secondary objective was to evaluate the effect of CM treatment on milk yield, reproductive performance, and survival of dairy cows.

\section{MATERIALS AND METHODS}

\section{Cows, Housing and Feeding Management}

All animal procedures were approved by the University of Florida Institutional Animal Care and Use Committee (IACUC protocol number 201509189). The study was conducted in 3 dairy herds located in North Central Florida from May, 2016 to June, 2017. Herds $\mathrm{A}, \mathrm{B}$, and $\mathrm{C}$ had 4,400, 1,800, and 450 lactating cows, respectively. All herds milked only Holstein cows. In herds $\mathrm{A}$ and $\mathrm{B}$, cows were milked 3 times daily and in herd C, cows were milked twice a day. The rolling herd average milk yield ranged from 10,500 to $12,000 \mathrm{~kg}$. Individual milk weights were recorded at every milking on farms A and C, and monthly on farm B. Production and reproduction data were stored in the farm management software PCDart (Dairy Records Management Systems, Raleigh, NC) in farm A and C, and AfiFarm 5.4 (Afimilk, Kibbutz Afikim, Israel) in farm B. Postpartum pens had sand-bedded stalls and were equipped with sprinklers over the feeding areas that activated when the environmental temperature rose above $>21^{\circ} \mathrm{C}$. The postpartum diet was formulated to meet or exceed the dietary nutrient requirements for a lactating cow weighing $680 \mathrm{~kg}$ and producing $45 \mathrm{~kg}$ of $3.5 \%$ FCM with $3.0 \%$ protein (NRC, 2001). This diet was delivered as a TMR twice daily.

\section{Sample Size Calculation}

For evaluation of the efficacy of intrauterine administration of CM for the treatment of metritis, the sample size was calculated to detect treatment differences in metritis cure of 10 percentage units, assuming a cure rate of $75 \%$ for $\mathrm{CM}$ and $\mathrm{CEF}$, and up to $65 \%$ for CON (Chenault et al., 2004; McLaughlin et al., 2012). With $\alpha$ of $5 \%$ and $80 \%$ power, a maximum sample size of 259 cows per group was needed. Nonetheless, we aimed to enroll 275 cows per group to allow for up to $6 \%$ attrition. 


\section{Chitosan Microparticles Preparation and Dose of Administration}

Chitosan microparticles were prepared as previously reported (Jeon et al., 2014). Briefly, chitosan was purchased from Sigma-Aldrich (Sigma Chemical Co., St. Louis, MO), and a $1 \%$ (wt/vol) chitosan solution was prepared in $2 \%$ acetic acid ( $\mathrm{vol} / \mathrm{vol})$ and $1 \%$ Tween 80 (vol/vol). To facilitate cross-linking, the chitosan solution was stirred and sonicated with the addition of $2 \mathrm{~mL}$ of sodium sulfate $(10 \% \mathrm{wt} / \mathrm{vol})$ into $100 \mathrm{~mL}$ of chitosan solution. The total sonication time and sonication power was varied to obtain the desired chitosan microparticle size $(\sim 0.6 \mu \mathrm{m})$. Chitosan microparticles were collected by centrifugation $(12,000 \times g)$ for 10 min, washed 3 times with sterile water, aliquoted, and stored at $4^{\circ} \mathrm{C}$ to be used in the experiments.

To determine the dose of administration, we evaluated the antimicrobial activity of CM ex vivo using autoclaved uterine discharge from 3 cows with metritis (Ma et al., 2015). We inoculated $5 \times 10^{4} \mathrm{cfu} / \mathrm{mL}$ of Escherichia coli isolated from cows with metritis in the uterine fluid, and tested the antimicrobial activity of $\mathrm{CM}$ ranging from 0.1 to $0.8 \%$. A CM concentration of $0.6 \%$ was required to eliminate all the E. coli in uterine fluid. Therefore, the dose of CM administration in the uterus was determined to be $24 \mathrm{~g}$ to give a final concentration of at least $0.6 \%$, assuming a uterine content in cows with metritis of $4 \mathrm{~L}(24 / 4,000 \times 100$ $=0.6 \%)$. The estimate of $4 \mathrm{~L}$ was based on necropsy findings and previous work from our group and others (Gier and Marion, 1968; Mateus et al., 2002; Juchem et al., 2010); the previously pregnant uterine horn of cows with metritis had a maximum diameter of $8 \mathrm{~cm}$ and a length of $50 \mathrm{~cm}$, and the nonpregnant uterine horn had a maximum diameter of $6 \mathrm{~cm}$ and a length of approximately $40 \mathrm{~cm}$ (volume $=\pi \times \mathrm{r}^{2} \times$ length, $\mathrm{r}$ $=$ radius $)$.

\section{Eligibility Criteria and Metritis Diagnosis}

Cows calving within the withdrawal period for any antimicrobial agent, cows treated with any antimicrobial, steroidal or nonsteroidal anti-inflammatory, or antipyretic agents between calving and metritis diagnosis, cows submitted to caesarian section or fetotomy, cows that aborted ( $<260 \mathrm{~d}$ of gestation), cows that had uterine prolapse after delivery, and cows diagnosed with infectious (e.g., mastitis, gastroenteritis, pneumonia, peritonitis) or digestive (i.e., displaced abomasum) diseases at the time of metritis diagnosis were not eligible for enrollment in the experiment.

Cows were examined for diagnosis of metritis at 5 , 7, and 9 DIM using the Metricheck device (Simcro,
Hamilton, New Zealand) by members of the research team (Galvão, Daetz, Cunha, and de Oliveira). The research members Galvão, Daetz, and Cunha had diagnosed at least 1,000 cows for metritis before the experiment started; de Oliveira was trained by Galvão. Discharge retrieved from the vagina was scored as: $1=$ not fetid normal lochia, viscous, clear, red, or brown; 2 = cloudy mucoid discharge with flecks of pus; $3=$ not fetid, mucopurulent discharge with $<50 \%$ pus; $4=$ not fetid mucopurulent white, yellow or reddish-brownish discharge with $\geq 50 \%$ pus; and $5=$ fetid, thin, serous, or watery, may have been reddish-brownish, with or without pieces of necrotic tissue present (adapted from Chenault et al., 2004). Cows with a vaginal discharge score of 5 were classified as having metritis. The mean, standard deviation, minimum and maximum for the DIM at metritis diagnosis were 7.4, 2.2, 7, 2, and 21 DIM, respectively.

The Metricheck tool has been compared with other common methods for evaluation of vaginal discharge for diagnosis of uterine disease such as a cytology, manual evaluation, and vaginoscopy, and it was found to have higher sensitivity than vaginoscopy for the diagnosis of endometritis (McDougall et al., 2007; Pleticha et al., 2009). Furthermore, cows diagnosed with endometritis using the Metricheck device had decreased reproductive performance (McDougall et al., 2007; Pleticha et al., 2009).

\section{Treatment Assignment}

Cows diagnosed with metritis were blocked by parity (primiparous or multiparous) and, within each block, were randomly assigned to 1 of 3 treatments: (1) CM ( $\mathrm{n}=276 ; 149$ primiparous and 127 multiparous $)=$ intrauterine infusion of $24 \mathrm{~g}$ of CM dissolved in $40 \mathrm{~mL}$ of sterile distilled water on d 0 (diagnosis/enrollment), d 2 , and $\mathrm{d} 4$. The intrauterine infusions were performed after the vulva was cleaned using $70 \%$ alcohol. A single rounded tip pipette (Uter flush pipetes10 G01, Van Beek, Orange City, IA) was used to deliver the solution into the uterine lumen; (2) CEF ( $\mathrm{n}=275 ; 147$ primiparous and 128 multiparous) $=$ subcutaneous injections of $6.6 \mathrm{mg} / \mathrm{kg}$ ceftiofur crystalline-free acid (Excede, Zoetis, Parsippany, NJ) in the base of the ear at $\mathrm{d} 0$ and $\mathrm{d}$ 3. Live BW was estimated using a heart girth measuring tape (Nasco Inc., Atkinson, WI); (3) CON ( $\mathrm{n}=275 ; 139$ primiparous and 136 multiparous) $=$ no treatment at the time of metritis diagnosis. Treatments were performed by members of the research team (Galvão, Daetz, Cunha, and de Oliveira). Cows with a vaginal discharge $\leq 3$ were classified as nonmetritic (NMET; $\mathrm{n}=2,436 ; 647$ primiparous and $1789 \mathrm{mul}-$ tiparous). 
At 5 DIM all cows were scored for body condition $(1=$ thin, $5=$ obese; Ferguson et al., 1994) and vaginal-vulvar laceration (VLS; $0=$ no laceration, 1 $=$ laceration $<2 \mathrm{~cm}$ at dorsal commissure or internal vaginal wall, $2=$ vaginal-vulvar laceration $>2 \mathrm{~cm}$; Viera-Neto et al., 2016). At enrollment, all cows had rectal temperature measured with a thermometer that was calibrated daily before use, and cows with rectal temperature $\geq 39.5^{\circ} \mathrm{C}$ were considered febrile.

\section{Cure of Metritis and Escape Therapy}

At $6 \mathrm{~d}$ and $12 \mathrm{~d}$ after enrollment, all cows in the $\mathrm{CM}$, CEF, and CON treatments were re-examined using the Metricheck device. Nonmetritic cows were not re-examined after the last examination at 9 DIM. Cows previously diagnosed with metritis that had a vaginal discharge score of $<5$ on d 6 or d 12 after enrollment were considered to have been cured. Thus, cows with a vaginal discharge score of 5 and cows that were sold or died $\leq 12 \mathrm{~d}$ after enrollment were considered a treatment failure. A veterinarian from the research team who was unaware of treatment assignment performed the post-enrollment exam on d 12. It is worth noting that the diagnosis of metritis and metritis cure based on vaginal discharge is subjective (Chenault et al., 2004; McLaughlin et al., 2012); therefore, it is subject to misclassification. Nonetheless, similar to previous studies (Chenault et al., 2004; McLaughlin et al., 2012), we believe the outcomes were not biased in favor or against any of the groups because of randomization of treatments and blinding during evaluation.

Escape therapy with an antibiotic of choice was allowed for all groups $1 \mathrm{~d}$ after enrollment. Criteria for escape therapy were severe dehydration, anorexia, weakness, severe depression, systemic shock, or any other clinical signs that were attributable to metritis (McLaughlin et al., 2012). Presence of only a vaginal discharge score of 5 and rectal temperature $\geq 39.5^{\circ} \mathrm{C}$ was not cause for escape therapy. The escape therapy was initiated by the herdsmen in each farm following the criteria described above, but without consultation with the research team. The herdsmen were unaware of treatment assignment. The escape therapy followed each herds' standard treatment protocols. Cows that received escape therapy were considered a treatment failure. Cows that did not receive antibiotics but received support therapy with hypertonic saline, oral electrolytes, dextrose, aspirin, meloxicam, or flunixin meglumine were not considered to have received escape therapy. The proportion of cows receiving support therapy that included the use of a nonsteroidal antiinflammatory agent was recorded.
A physical examination was performed by the herd veterinarian or by a veterinarian from the Food Animal Reproduction and Medicine Service (FARMS) from University of Florida in all cows that were sold. A necropsy examination was performed by the herd veterinarian or a veterinarian from the food animal reproduction and medicine service from University of Florida in all the cows that died within 60 DIM. The reasons for culling (sold or died) within 60 DIM were recorded for all enrolled cows in the experiment. The reasons listed were metritis, pelvic inflammation, peritonitis, mass in the pelvic cavity, mastitis, injury to teat or udder, lung abscess, fatty liver, digestive issues, trauma, sudden death, and low milk yield. Reason for culling were classified as uterine related (i.e., metritis, pelvic inflammation, peritonitis, and mass in the pelvis), non-uterine-related (i.e., mastitis, injury to teat or udder, lung abscess, fatty liver, digestive issues, trauma, sudden death), and low milk yield. The diagnosis of peritonitis antemortem was defined as the presence of granular, gritty feel, with an impression of an abnormal freedom of movement within the abdominal cavity at rectal palpation and pelvic inflammation. The diagnosis of lung abscesses and fatty liver were made postmortem during necropsy.

\section{Reproductive Management and Reproductive Performance}

In herd A, the voluntary waiting period was 48 DIM, and cows were artificially inseminated when detected in estrus by visual observation or by the use of a heat detection device (Kamar, Kamar Inc., Steamboat Springs, CO). Cows that had not been inseminated by $55 \pm 3$ DIM received one injection of $\mathrm{PGF}_{2 \alpha}$ and were inseminated upon estrus detection thereafter. Cows not observed in estrus by $72 \pm 3$ DIM were submitted to the Ovsynch protocol $\left(\mathrm{GnRH}\right.$ on $\mathrm{d} 0, \mathrm{PGF}_{2 \alpha}$ on $\mathrm{d} 7$, GnRH on d 9, AI on d 10) and were fixed-time AI at 82 \pm 3 DIM. The diagnoses of pregnancy were performed by transrectal ultrasonography (Easi-Scan linear bovine ultrasound machine, IMV Imaging, North America Inc., Rochester, MN) at $33 \pm 3 \mathrm{~d}$ after service. In herd $\mathrm{B}$, the voluntary waiting period was 50 DIM, and cows not detected in estrus by the use of tail paint heat detection aid and inseminated by 70 DIM were enrolled in an Ovsynch protocol. The diagnoses of pregnancy were performed by the farm personnel through rectal palpation of the uterine contents at $42 \pm 3 \mathrm{~d}$. In herd $\mathrm{C}$, cows were enrolled in a Double-Ovsynch protocol at $54 \pm 3$ DIM $\left(\mathrm{GnRH}\right.$ on $\mathrm{d}-17, \mathrm{PGF}_{2 \alpha}$ on $\mathrm{d}-10$, GnRH on $\mathrm{d}-7, \mathrm{GnRH}$ on $\mathrm{d} 0, \mathrm{PGF}_{2 \alpha}$ on $\mathrm{d} 7, \mathrm{GnRH}$ on $\mathrm{d} 9$, AI on $\mathrm{d} 10)$. The diagnoses of pregnancy were 
performed by transrectal ultrasonography with the Easi-Scan linear bovine ultrasound machine at $33 \pm 3$ d after service. Nonpregnant cows were resynchronized using the Ovsynch protocol in all herds. All of the AI and pregnancy diagnoses were recorded on the on-farm management software by the herd personnel. Weekly backups were saved and used to retrieve reproductive performance data. Ultrasonography was performed by members of the research team (Galvão, Daetz, Cunha, and de Oliveira) at $36 \pm 3$ and $50 \pm 3$ DIM to determine cyclicity status based on the presence of a visible corpus luteum in herd A. Galvão, Daetz, Cunha, and de Oliveira had performed at least 1,000 ultrasonographies for diagnosis of ovarian structures before the experiment started. Pregnancy per AI at first service and time to pregnancy up to 300 DIM were calculated for all cows enrolled in the experiment.

\section{Blood Metabolite Concentrations and Rectal Temperature}

Blood samples were collected in evacuated tubes (Vacutainer, Becton Dickinson and Company, Franklin Lakes, NJ) containing $\mathrm{K}_{2}$ EDTA at d 0 , d 3, d 6, d 9 and d 12 from a subset of 200 cows (50 per group) from herd A by puncture of the coccygeal vein or artery. On d 0 and d 3, blood was sampled before treatments with $\mathrm{CM}, \mathrm{CEF}$, or both. For cows in the NMET group, d 0 averaged $6.7 \pm 1.6(\mathrm{SD})$ DIM. Rectal temperature was measured at the same time points immediately before blood collection. Blood samples were maintained on ice until plasma was harvested by centrifuging tubes at $2000 \times g$ for 10 min (Heraeus Megafuge 1.0; Thermo Fisher Scientific Inc., Waltham, MA). Plasma was transferred to 2 polypropylene vials and stored at $-80^{\circ} \mathrm{C}$ until assayed for NEFA, BHB, and Hp.

Concentrations of NEFA were analyzed by a chemistry analyzer (RX DaytoNa ${ }^{+}$, Randox Laboratories Ltd.) in a single assay and the inter-assay CV was $5.1 \%$. Concentrations of BHB in plasma were analyzed by chemistry analyzer in a single assay and the interassay CV was $4.2 \%$. Plasma Hp concentration was determined using a colorimetric assay via quantification of the haptoglobin-hemoglobin complex by the estimation of differences in peroxidase activity. Assays were performed in $16 \times 100 \mathrm{~mm}$ borosilicate tubes. Briefly, $5 \mu \mathrm{L}$ of plasma sample or deionized water (blank) was added to $7.5 \mathrm{~mL}$ of a solution containing $0.6 \mathrm{~g} / \mathrm{L}$ of the reagent $\mathrm{O}$ dianisidine, $13.8 \mathrm{~g} / \mathrm{L}$ of sodium phosphate monobasic, and $0.5 \mathrm{~g} / \mathrm{L}$ of EDTA. We then added 25 $\mu \mathrm{L}$ of $0.3 \mathrm{~g} / \mathrm{L}$ bovine hemoglobin solution to each assay, followed by water bath incubation at $37^{\circ} \mathrm{C}$ for $45 \mathrm{~min}$. After incubation, $100 \mu \mathrm{L}$ of freshly prepared $156 \mathrm{mM}$ hydrogen peroxidase solution was added to each assay.
Samples were incubated at room temperature for 60 min. Then, $200 \mu \mathrm{L}$ of each assay was transferred to a 96-well polystyrene flat-bottom microplate. Optical density (OD) at $450 \mathrm{~nm}$ was measured on the Epoch2 Microplate Spectrophotometer (BioTek, Winooski, VT). Finally, the final OD of each assay was subtracted by the blank assay OD. Optical density data were converted to a concentration unit $(\mu \mathrm{g} / \mathrm{mL})$ using standard curves generated by serial dilutions of a sample of known concentration determined by ELISA (Life Technologies, West Chester, PA) as previously described (Cooke and Arthington, 2013). The intra- and inter-assay CV were 6.9 and $7.7 \%$, respectively.

\section{Statistical Analysis}

Discrete data (lactation number) and score data (BCS and VLS) were compared nonparametrically using the NPAR1WAY procedure of SAS version 9.3 (SAS Institute, Cary, NC). Mean and SEM were presented and the Kruskal-Wallis test was used to compare the treatment groups.

Binary outcomes, such as proportion of cows with a fever on $\mathrm{d} 0$, proportion of cows receiving support therapy that included the use of a nonsteroidal antiinflammatory agents, proportion of cows receiving escape therapy, cure of metritis, sold within 60 DIM, died within 60 DIM, culled within 60 DIM, proportion coded as do not breed, and pregnancy per AI were analyzed by mixed logistic regression using the GLIMMIX procedure of SAS. The model included the fixed effects of treatment (CM, CEF, CON), season [cool (d 0 from September to May) vs. hot (d 0 from June to August)], fever (yes vs. no), parity (primiparous vs. multiparous), BCS (>3.0 vs. $\leq 3.0$ ), dystocia (yes vs. no), RFM (yes vs. no), VLS ( 2 vs. $<2$ ), and 2-way interactions between treatment and other covariates. Animal identification nested within herd was included as a random effect. The LSMEANS statement was used to compute least squares means (LSM) and standard error (SE) of the means for fixed effects. In a binomial model with logit link, the LSM are predicted population margins of the logits. When an interaction was detected, then mean separation was assessed using the SLICE option.

Continuous outcomes such as rectal temperature, plasma concentrations of NEFA, BHB, and Hp, daily milk yield during the first 60 DIM, and monthly milk yield during the first 300 DIM were analyzed by ANOVA for repeated measures using the MIXED procedure of SAS. Models included the fixed effects of treatment, time, season, parity, BCS, dystocia, RFM, VLS, and 2-way interactions between treatment and other covariates. Herd was included as a fixed effect in the models for daily milk yield during the first 60 
DIM, and monthly milk yield during the first 300 DIM. Rectal temperature or analyte concentrations at the time of metritis diagnosis and DIM at enrollment were included in the repeated measures models as covariates. Animal identification nested within treatment was included as a random effect in all models. The LSMEANS statement was used to compute LSM and $\mathrm{SE}$ of the means for fixed effects. When an interaction was detected, then mean separation was assessed using the SLICE option.

Hazard of culling up to 300 DIM was analyzed by Cox's proportional hazard model using the PHREG procedure of SAS. Models included, as appropriate, the fixed effects of treatment, season, parity, BCS, dystocia, RFM, VLS, and interactions between treatment and other covariates. Herd was included as strata. Because treatment affected the proportion of cows culled, the hazard of culling, and the proportion of cows coded as do not breed (DNB), and once a cow is coded as DNB or culled she is not at risk of becoming pregnant, a competing risk regression was used to analyze the effect of treatment on the hazard of pregnancy up to 300 DIM, using the PHREG procedure of SAS (Guo and So, 2018). In the analysis, cows coded as DNB or culled were treated as a competing risk. A competing risk model makes no assumptions about the independence of outcomes, namely DNB or culling and pregnancy, and the cause-specific hazard estimates compare the probability of pregnancy for each treatment group, conditional upon occurrence of the competing risk (Fine and Gray, 1999). Kaplan-Meier survival curves were built using MedCalc version 19 (Ostend, Belgium). For all the models, a backward elimination was performed, and covariates were excluded from the models when $P$ $>0.10$. Treatment was forced in all the models. For comparison, a separate analysis was run adding the NMET group, using the final model for each outcome. For all the analyses, differences detected at $P \leq 0.05$ were considered significant, and differences at $0.05<$ $P<0.10$ were considered a tendency toward statistical significance.

\section{RESULTS}

\section{Descriptive Statistics}

There were 276 cows (149 primiparous and 127 multiparous) assigned to CM, 275 (47 primiparous and 128 multiparous) assigned to CEF, and 275 (139 primiparous and 136 multiparous) assigned to CON. In addition, there were 2,436 cows (647 primiparous and 1789 multiparous) classified as NMET. The lactation number was not different $(P=0.44)$ among $\mathrm{CM}, \mathrm{CEF}$, and $\mathrm{CON}(1.83 \pm 0.07$ vs. $1.87 \pm 0.07$ vs. $1.97 \pm 0.07$, respectively). The BCS was different $(P=0.02)$ among treatment groups; it was lesser for CEF than CON $(3.40 \pm 0.02$ vs. $3.46 \pm 0.02 ; P<0.01)$, and tended to be lesser for CM than CON (3.42 \pm 0.02 vs. 3.46 $\pm 0.02 ; P=0.07)$. There was no difference $(P=0.34)$ between $\mathrm{CM}$ and $\mathrm{CEF}$. The VLS was not different $(P=$ $0.54)$ among $\mathrm{CM}, \mathrm{CEF}$, and $\mathrm{CON}(0.96 \pm 0.05$ vs. 0.89 \pm 0.05 vs. $0.89 \pm 0.05$, respectively). The proportion of cows with a fever on d 0 was not different $(P=0.49)$ among $\mathrm{CM}, \mathrm{CEF}$, and $\mathrm{CON}(51.3 \pm 0.1$ vs. $53.4 \pm 0.1$ vs. $48.3 \pm 0.1 \%$, respectively).

\section{Effect of Treatment on the Risk of Receiving Support Therapy, Escape Therapy, and Metritis Cure}

Treatment had an effect $(P<0.01)$ on the risk of receiving support therapy that included the use of a nonsteroidal anti-inflammatory agent. Cows in CM had greater $(P<0.01)$ risk of receiving support therapy than cows in $\mathrm{CEF}$ and $\mathrm{CON}(30.2 \pm 4.0$ vs. $8.6 \pm 2.2$ vs. $15.5 \pm 3.0 \%$, respectively). The risk of receiving support therapy was lesser $(P=0.04)$ in CEF than in CON.

Treatment had an effect $(P<0.01)$ on the risk of receiving antibiotic escape therapy. Cows in CM had greater $(P<0.01)$ risk of receiving antibiotic escape therapy than cows in $\mathrm{CEF}$ and CON (26.4 \pm 4.5 vs. $7.6 \pm 2.2$ vs. $11.5 \pm 2.9 \%$, respectively). The risk of receiving antibiotic escape therapy was not different $(P$ $=0.21$ ) between $\mathrm{CEF}$ and CON.

Treatment had an effect $(P<0.01)$ on the risk of metritis cure on $\mathrm{d} 6$. Cows in CM had lesser $(P<0.01)$ risk of metritis cure than cows in $\mathrm{CEF}$, and tended $(P$ $=0.06)$ to have lesser cure risk than CON $(36.8 \pm 5.0$ vs. $51.8 \pm 5.4$ vs. $44.7 \pm 5.4 \%$, respectively). Cure risk in CEF tended to be greater $(P=0.10)$ than in CON on d 6 (Figure 1A).

Treatment had an effect $(P<0.01)$ on the risk of metritis cure on $\mathrm{d} 12$. Cows in $\mathrm{CM}$ and $\mathrm{CON}$ had lesser $(P<0.01)$ risk of metritis cure than cows in CEF $(58.6$ \pm 5.0 vs. $61.9 \pm 4.9 \%$ vs. $77.9 \pm 3.9$, respectively). There was no difference $(P=0.44)$ between $\mathrm{CM}$ and CON (Figure 1B).

\section{Effect of Treatment on the Proportion of Cows that Were Sold, Died, and Were Culled Within 60 DIM}

Treatment affected $(P<0.01)$ the proportion of cows sold within 60 DIM (Figure 2A). The proportion of cows sold within 60 DIM was greater $(P<0.02)$ in $\mathrm{CM}$ than $\mathrm{CEF}$ and $\mathrm{CON}(11.3 \pm 3.0$ vs. $5.0 \pm 1.7$ vs. $6.1 \pm 1.9 \%$, respectively). No difference $(P=0.51)$ was observed between CEF and CON. For comparison, the proportion of cows sold by 60 DIM in the NMET group 
was $2.8 \pm 0.5 \%$, and it was lesser $(P<0.01)$ than that in all the metritic groups (Supplemental Figure S1A, https://doi.org/10.3168/jds.2019-18028).

Treatment had no effect $(P=0.13)$ on the proportion of cows that died within 60 DIM (Figure 2B). Nonethe-
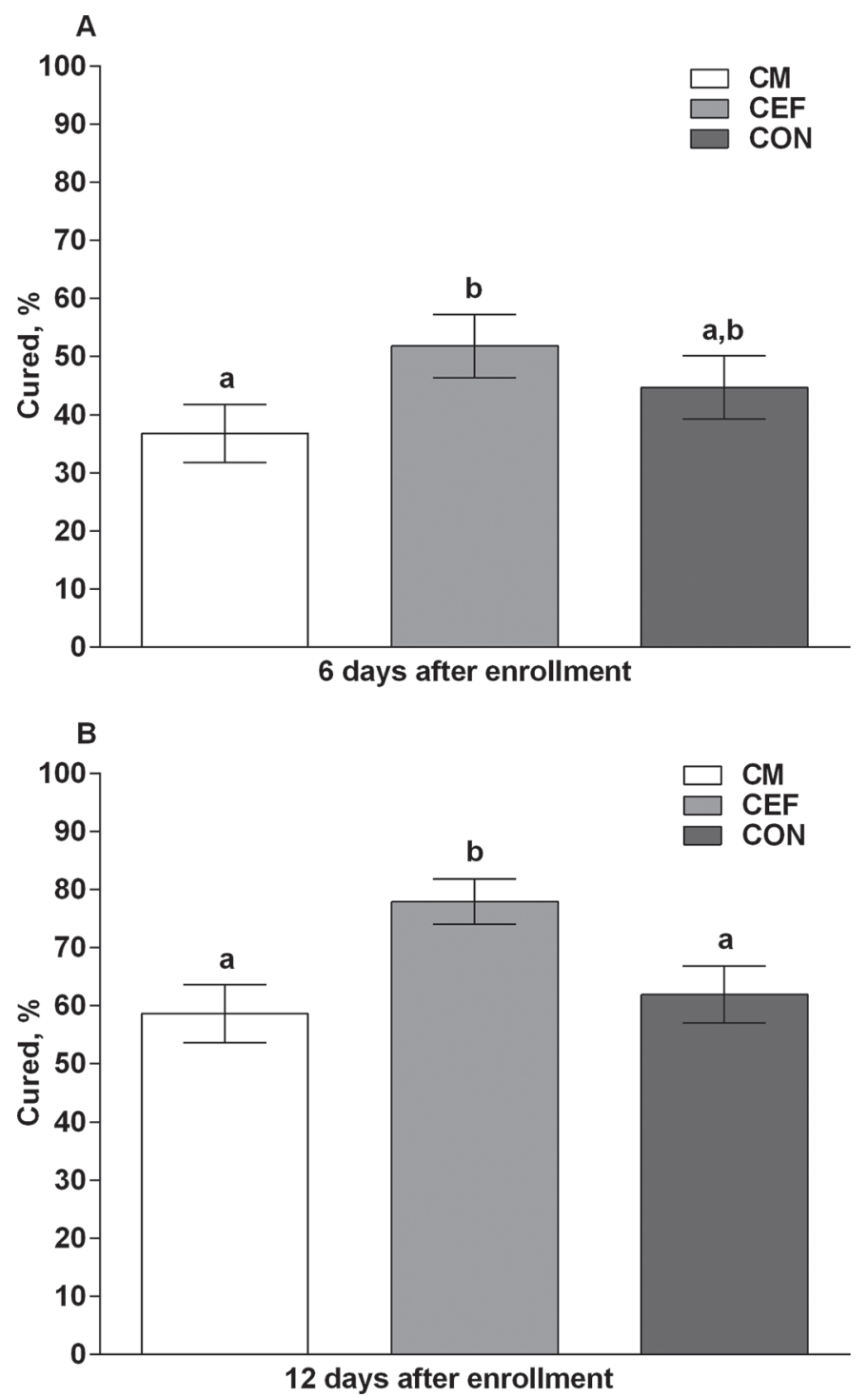

Figure 1. Proportion of cows cured of metritis on d 6 (A) and 12 (B) after enrollment according to treatment used. Metritis was diagnosed in cows with a vaginal discharge that was fetid, thin, serous, or watery, reddish-brownish, and with or without pieces of necrotic tissue. Cows diagnosed with metritis were assigned randomly to receive CM $(\mathrm{n}=276)$, an intrauterine infusion of $24 \mathrm{~g}$ of chitosan microparticles dissolved in $40 \mathrm{~mL}$ of sterile distilled water on d 0,2 , and 4 after diagnosis of metritis; CEF ( $\mathrm{n}=275$ ), a subcutaneous injection of 6.6 $\mathrm{mg} / \mathrm{kg}$ ceftiofur crystalline-free acid (Excede, Zoetis, Parsippany, NJ) at the time of diagnosis of metritis and $3 \mathrm{~d}$ later; or CON $(\mathrm{n}=275)$, no treatment at the time of diagnosis. There was an effect of treatment $(P \leq 0.01)$ on the proportion of cows cured of metritis on $\mathrm{d} 6$ and on $\mathrm{d}$ 12 after enrollment. Letters $(\mathrm{a}, \mathrm{b})$ indicate significant differences $(P \leq$ $0.05)$ among treatments after Tukey-Kramer adjustments. Error bars indicate SEM.
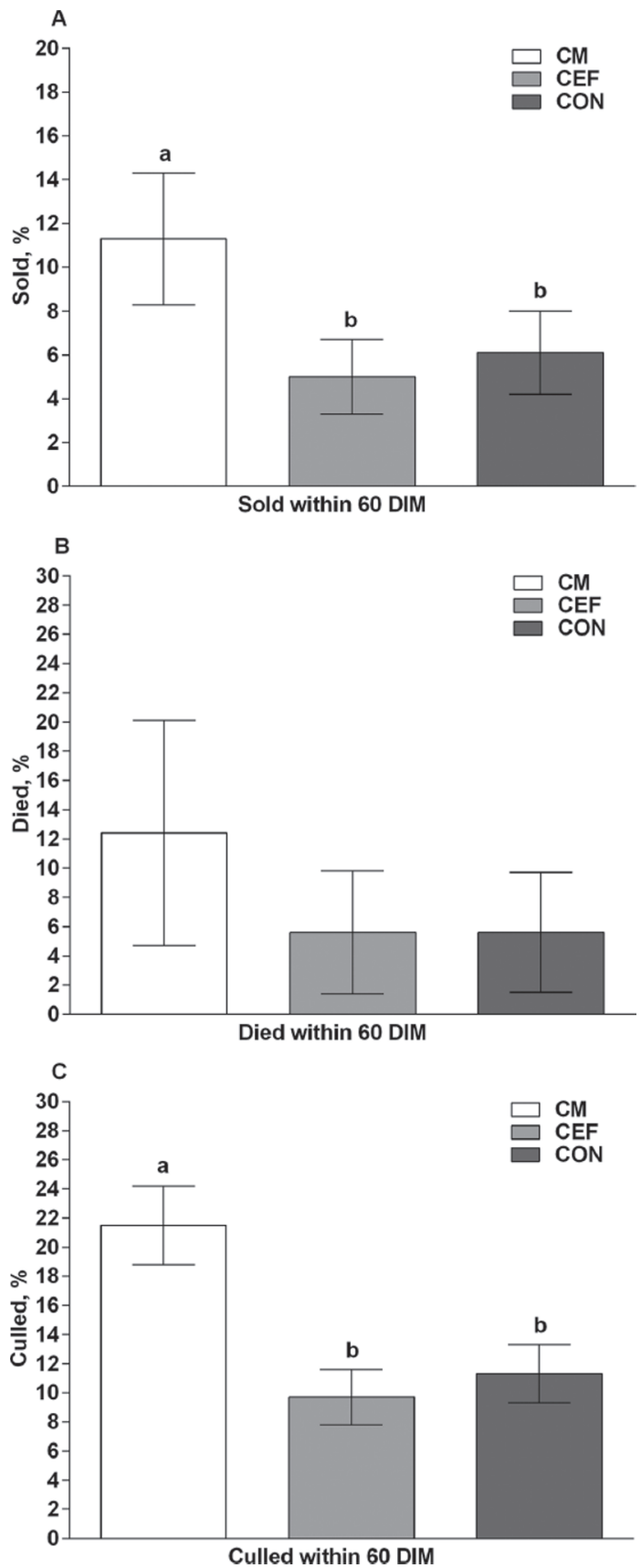

Figure 2. Proportion of cows that were sold (A), died (B), and were culled (C) within 60 DIM according to treatment used. Metritis was diagnosed in cows with a vaginal discharge that was fetid, thin serous, or watery, reddish-brownish, and with or without pieces of necrotic tissue. Cows diagnosed with metritis were assigned randomly to receive CM $(\mathrm{n}=276)$, intrauterine infusion of $24 \mathrm{~g}$ of chitosan microparticles dissolved in $40 \mathrm{~mL}$ of sterile distilled water on d 0,2 , and 4 after diagnosis of metritis; CEF $(\mathrm{n}=275)$, a subcutaneous injection of $6.6 \mathrm{mg} / \mathrm{kg}$ ceftiofur crystalline-free acid (Excede, Zoetis, Parsippany, NJ) at the time of diagnosis of metritis and $3 \mathrm{~d}$ later; or CON ( $\mathrm{n}=$ $275)$, no treatment at the time of diagnosis. There was an effect of treatment $(P \leq 0.01)$ on the proportion of cows sold and culled within 60 DIM. Treatment did not affect $(P=0.13)$ the proportion of cows that died within 60 DIM. Letters $(\mathrm{a}, \mathrm{b})$ indicate significant differences $(P \leq 0.05)$ among treatments after Tukey-Kramer adjustments. Error bars indicate SEM. 

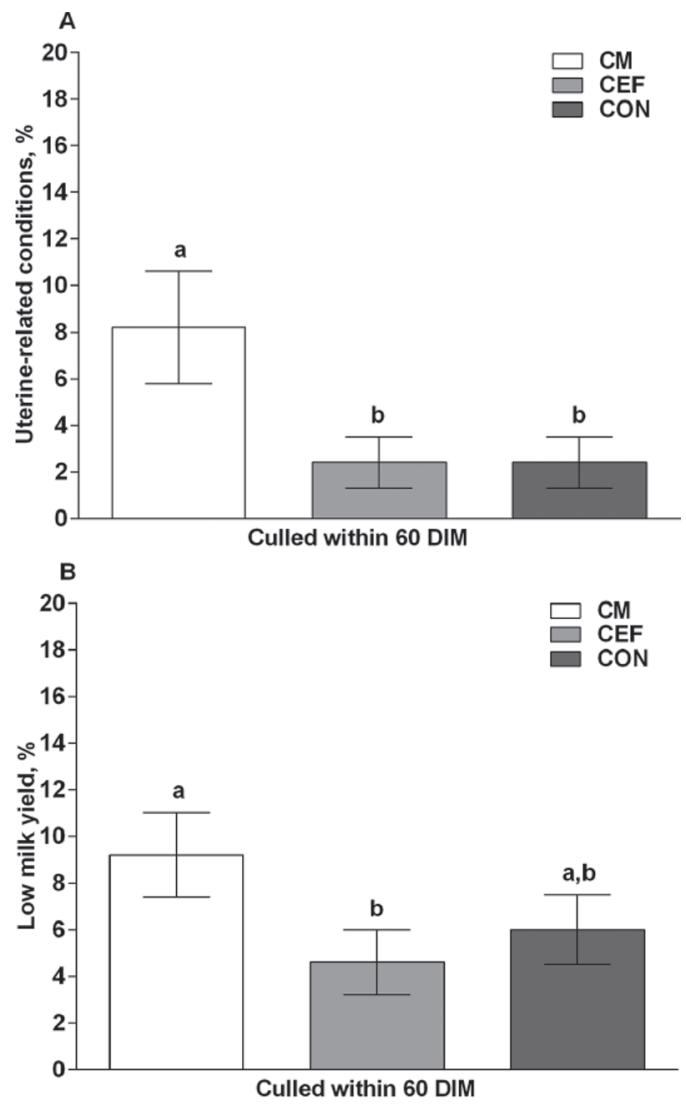

less, the trend was similar to proportion of cows sold within 60 DIM, with numerically greater proportion of cows that died within 60 DIM for CM than CEF and CON (12.4 \pm 7.7 vs. $5.6 \pm 4.2$ vs. $5.6 \pm 4.1 \%$, respectively). For comparison, the proportion of cows sold within 60 DIM in the NMET group was $1.5 \pm 0.8 \%$, and it was lesser $(P<0.01)$ than that in all the metritic groups (Supplemental Figure S1B, https://doi.org/10 $.3168 /$ jds.2019-18028).

Treatment had an effect $(P<0.01)$ on the overall proportion of cows culled within 60 DIM. The proportion of cows culled within 60 DIM was greater $(P<$ 0.01) for cows in CM than for cows in CEF and CON $(21.5 \pm 2.7$ vs. $9.7 \pm 1.9$ vs. $11.3 \pm 2.0 \%$, respectively $)$. No difference $(P=0.55)$ was observed between CEF and $\mathrm{CON}$ (Figure 2C). For comparison, the proportion of cows culled within 60 DIM in the NMET group was $4.0 \pm 0.5 \%$, and it was lesser $(P<0.01)$ than all the metritic groups (Supplemental Figure S1C, https://doi .org/10.3168/jds.2019-18028).

\section{Effect of Treatment on Reasons for Culling Within 60 DIM}

Treatment had an effect $(P<0.01)$ on culling within 60 DIM because of uterine related conditions (Figure $3 \mathrm{~A})$. The proportion of cows culled within 60 DIM because of uterine related conditions was greater $(P \leq$ 0.01) in $\mathrm{CM}$ than in $\mathrm{CEF}$ and $\mathrm{CON}(8.2 \pm 2.4$ vs. 2.4 \pm 1.1 vs. $2.4 \pm 1.1 \%$, respectively).

Treatment tended to have an effect $(P=0.10)$ on culling within 60 DIM because of low milk yield (Figure $3 \mathrm{~B})$. The proportion of cows culled within 60 DIM because of low milk yield was greater $(P=0.05)$ in $\mathrm{CM}$ than in $\mathrm{CEF}$, but was not different $(P=0.18)$ from $\mathrm{CON}(9.2 \pm 1.8$ vs. $4.6 \pm 1.4$ vs. $6.0 \pm 1.5 \%$, respectively).

Treatment had no effect $(P=0.86)$ on culling within 60 DIM because of non-uterine-related conditions (Figure $3 \mathrm{C}$ ). The proportion of cows culled within $60 \mathrm{DIM}$ because of non-uterine-related conditions was $2.5 \pm$ $0.9,1.9 \pm 0.8$, and $2.1 \pm 0.9 \%$ for CM, CEF and CON, respectively.

uterine conditions (A), low milk yield (B), and non-uterine-related conditions $(\mathrm{C}$ ) according to treatment used. Metritis was diagnosed in cows with a vaginal discharge that was fetid, thin, serous, or watery, reddish-brownish, and with or without pieces of necrotic tissue. Cows diagnosed with metritis were assigned randomly to receive CM ( $\mathrm{n}=$ 276 ), intrauterine infusion of $24 \mathrm{~g}$ of chitosan microparticles dissolved in $40 \mathrm{~mL}$ of sterile distilled water on $\mathrm{d} 0,2$, and 4 after diagnosis of metritis; CEF ( $\mathrm{n}=275$ ), a subcutaneous injection of $6.6 \mathrm{mg} / \mathrm{kg}$ ceftiofur crystalline-free acid (Excede, Zoetis, Parsippany, NJ) at the time of diagnosis of metritis and $3 \mathrm{~d}$ later; or CON $(\mathrm{n}=275)$, no treatment at the time of diagnosis. There was an effect of treatment $(P<0.01)$ on the proportion of cows culled within 60 DIM because of uterine conditions. Treatment tended to have an effect $(P=0.10)$ on culling within 60 DIM because of low milk yield. Treatment did not affect $(P=$ 0.86 ) culling within 60 DIM because of non-uterine-related conditions. Letters $(\mathrm{a}, \mathrm{b})$ indicate significant differences $(P \leq 0.05)$ among treatments after Tukey-Kramer adjustments. Error bars indicate SEM.

\section{Effect of Treatment on Rectal Temperature and Plasma Hp Concentration}

Treatment had no effect on rectal temperature on $\mathrm{d}$ $0(P=0.48)$ or d 3 to d $12(P=0.50$; Figure $4 \mathrm{~A})$; however, there was an interaction between treatment and time $(P<0.01)$ on rectal temperature from $\mathrm{d} 3$ to $\mathrm{d}$ 12 , which showed that rectal temperature was lesser $(P$ $<0.04)$ for CM and CEF than for CON on d 12 (38.9 \pm 0.03 vs. $38.9 \pm 0.03$ vs. $39.0 \pm 0.03^{\circ} \mathrm{C}$, respectively). 
There was also an effect of time $(P<0.01)$, which showed that rectal temperature decreased steadily from d 3 to $d 12$. For comparison, rectal temperature in the NMET group was lesser $(P<0.02)$ than that in the metritic groups on d 0 and from d 3 to d 12 (Supplemental Figure S2A, https://doi.org/10.3168/jds.2019 -18028).
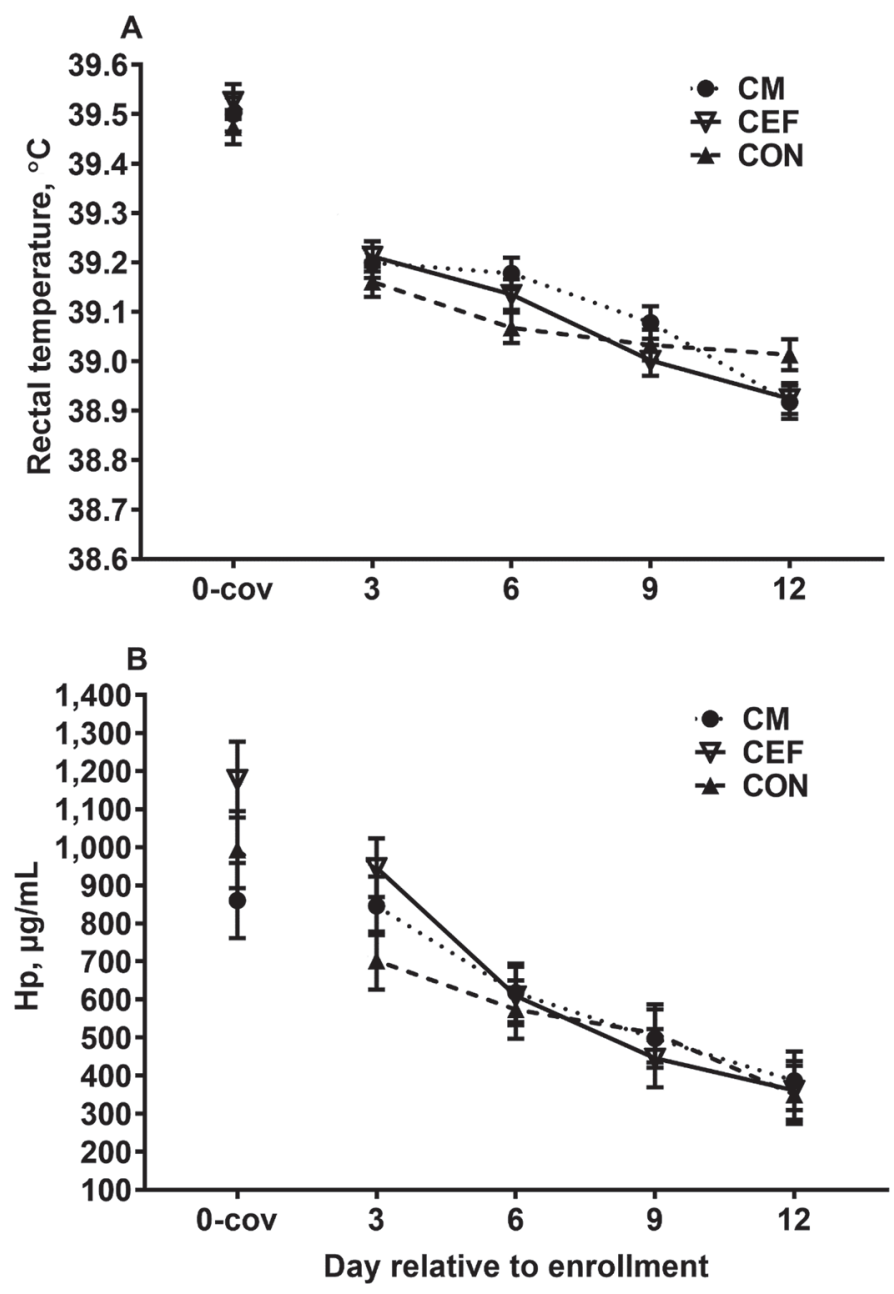

Figure 4. Least squares means $( \pm \mathrm{SE})$ of rectal temperature $\left({ }^{\circ} \mathrm{C}\right)$ (A) and of plasma concentrations of haptoglobin $(\mathrm{Hp}, \mu \mathrm{g} / \mathrm{mL})(B)$ for cows diagnosed with metritis, according to treatment used. Metritis was diagnosed in cows with a vaginal discharge that was fetid, thin, serous, or watery, reddish-brownish, and with or without pieces of necrotic tissue. Cows diagnosed with metritis were assigned randomly to receive $\mathrm{CM}(\mathrm{n}=50)$, intrauterine infusion of $24 \mathrm{~g}$ of chitosan microparticles dissolved in $40 \mathrm{~mL}$ of sterile distilled water on $\mathrm{d} 0,2$, and 4 after diagnosis of metritis; CEF $(n=50)$, a subcutaneous injection of $6.6 \mathrm{mg} / \mathrm{kg}$ ceftiofur crystalline-free acid (Excede, Zoetis, Parsippany, $\mathrm{NJ})$ at the time of diagnosis of metritis and $3 \mathrm{~d}$ later; CON $(\mathrm{n}=50)$, no treatment at the time of diagnosis. Day of enrollment (d 0) was analyzed separately and then used as a covariate (0-cov) in the repeated measures analysis. There was no effect of treatment $(P=0.50)$, but there was an effect of time $(P<0.01)$ and an interaction between treatment and time $(P<0.01)$ on rectal temperature. There was no effect of treatment $(P=0.08)$, but there was an effect of time $(P<$ $0.01)$ on plasma Hp concentration.
Treatment tended to affect plasma Hp concentration on d $0(P=0.08)$, and multiple comparisons showed that CM tended $(P=0.06)$ to have lesser Hp concentration than $\mathrm{CEF}$, but was similar to CON $(860 \pm 99$ vs. $1,178 \pm 100$ vs. $994 \pm 101 \mu \mathrm{g} / \mathrm{mL}$, respectively) (Figure 4B). Treatment did not affect plasma Hp concentration from d 3 to d $12(P=0.77)$, and there was no interaction $(P=0.23)$ between treatment and time on plasma $\mathrm{Hp}$ concentration from d 3 to $\mathrm{d} 12$. There was an effect of day $(P<0.01)$, which showed that plasma Hp concentration decreased steadily from d 3 to d 12. For comparison, plasma Hp concentration tended $(P=0.09)$ to be lesser in NMET than $\mathrm{CM}$, and was lesser $(P<0.01)$ in NMET than CEF and CON on $\mathrm{d}$ 0 . Plasma Hp concentration was lesser $(P<0.01)$ in NMET than in CEF, but was similar $(P>0.11)$ to that in $\mathrm{CM}$ and CON from d 3 to d 12 (Supplemental Figure S2B, https://doi.org/10.3168/jds.2019-18028).

\section{Effect of Treatment on Plasma NEFA and BHB Concentration}

Treatment had no effect on plasma NEFA concentration on d $0(P=0.27)$ or from d 3 to d $12(P=$ 0.61 ; Figure 5A). No interaction was found between treatment and time on NEFA concentration from $\mathrm{d} 3$ to $\mathrm{d} 12(P=0.41)$. There was an effect of time $(P<$ $0.01)$, which showed that plasma NEFA concentration decreased steadily from d 3 to d 12 . For comparison, the plasma NEFA concentration in NMET was lesser $(P=0.04)$ than $\mathrm{CM}$, but similar to $\mathrm{CEF}$ and $\mathrm{CON}$ on d 0. Plasma NEFA concentration did not differ $(P>$ $0.35)$ between NMET and the metritic groups from $d 3$ to d 12 (Supplemental Figure S3A, https://doi.org/10 $.3168 /$ jds.2019-18028).

Treatment did not affect plasma BHB concentration on d $0(P=0.18)$ or from d 3 to d $12(P=0.21$; Figure $5 \mathrm{~B})$. There was no interaction $(P=0.48)$ between treatment and time on plasma BHB concentration from d 3 to $\mathrm{d} 12$. There was an effect of time $(P<0.01)$, which showed that plasma BHB concentration decreased steadily from d 3 to d 9 , then increased form d 9 to $\mathrm{d}$ 12. For comparison, the plasma BHB concentration in NMET was lesser $(P=0.04)$ than $\mathrm{CM}$, but similar to $\mathrm{CEF}$ and $\mathrm{CON}$ on $\mathrm{d}$ 0. Plasma BHB concentration did not differ $(P>0.20)$ between NMET and the metritic groups from d 3 to d 12 (Supplemental Figure S3B, https://doi.org/10.3168/jds.2019-18028).

\section{Effect of Treatment on Daily Milk Yield Within 60 DIM}

Treatment had an effect $(P<0.01)$ on milk yield within 60 DIM (Figure 6). All the groups differed $(P$ $<0.01$ ), and the milk yield within 60 DIM averaged 
$35.8 \pm 0.3,38.0 \pm 0.3$, and $36.6 \pm 0.3 \mathrm{~kg} / \mathrm{d}$ for CM, $\mathrm{CEF}$, and $\mathrm{CON}$, respectively. There was an interaction between treatment and time $(P=0.02)$, which showed that milk yield was similar among treatments until 10 DIM, different $(P<0.05)$ until 37 DIM, and then similar until 60 DIM. For comparison, the NMET group had greater milk yield $(41.0 \pm 0.1 \mathrm{~kg} / \mathrm{d} ; P<0.01)$ than all metritic groups (Supplemental Figure S4, https:// doi.org/10.3168/jds.2019-18028).

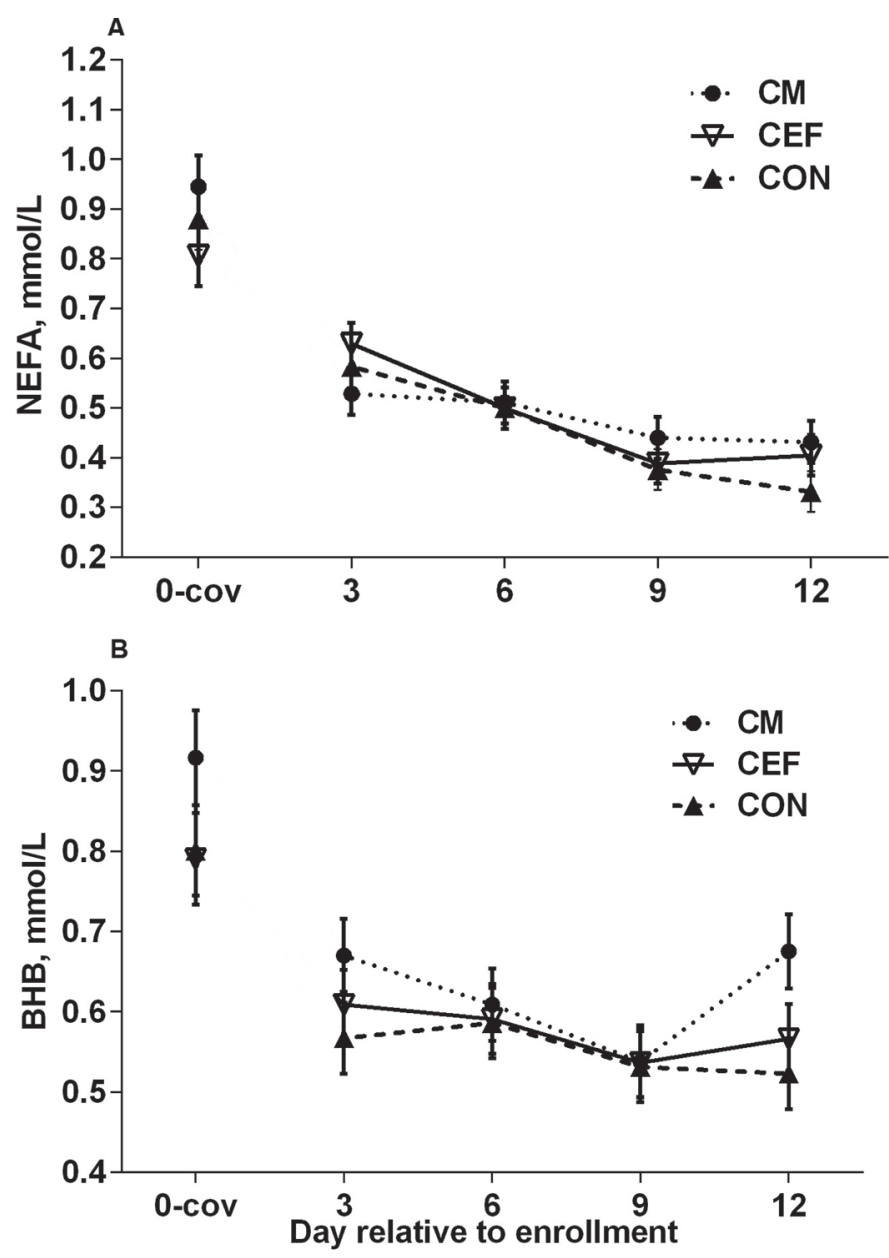

Figure 5. Least squares means $( \pm \mathrm{SE})$ of plasma concentrations of nonesterified fatty acids (NEFA; mmol/L) (A) and of plasma concentrations of $\mathrm{BHB}(\mathrm{mmol} / \mathrm{L})$ (B) for cows diagnosed with metritis according to treatment used. Metritis was diagnosed in cows with a vaginal discharge that was fetid, thin, serous, or watery, reddish-brownish, and with or without pieces of necrotic tissue. Cows diagnosed with metritis were assigned randomly to receive $\mathrm{CM}(\mathrm{n}=50)$, intrauterine infusion of $24 \mathrm{~g}$ of chitosan microparticles dissolved in $40 \mathrm{~mL}$ of sterile distilled water on $\mathrm{d} 0,2$, and 4 after diagnosis of metritis; CEF (n $=50$ ), a subcutaneous injection of $6.6 \mathrm{mg} / \mathrm{kg}$ ceftiofur crystallinefree acid (Excede, Zoetis, Parsippany, NJ) at the time of diagnosis of metritis and 3 d later; $\mathrm{CON}(\mathrm{n}=50)$, no treatment at the time of diagnosis. Day of enrollment (d 0) was analyzed separately and then used as a covariate $(0-$ cov $)$ in the repeated measures analysis. There was no effect of treatment $(P=0.61)$, but there was an effect of time $(P<0.01)$ on plasma NEFA concentration. There was no effect of treatment $(P=0.21)$, but there was an effect of time $(P<0.01)$ on plasma BHB concentration.

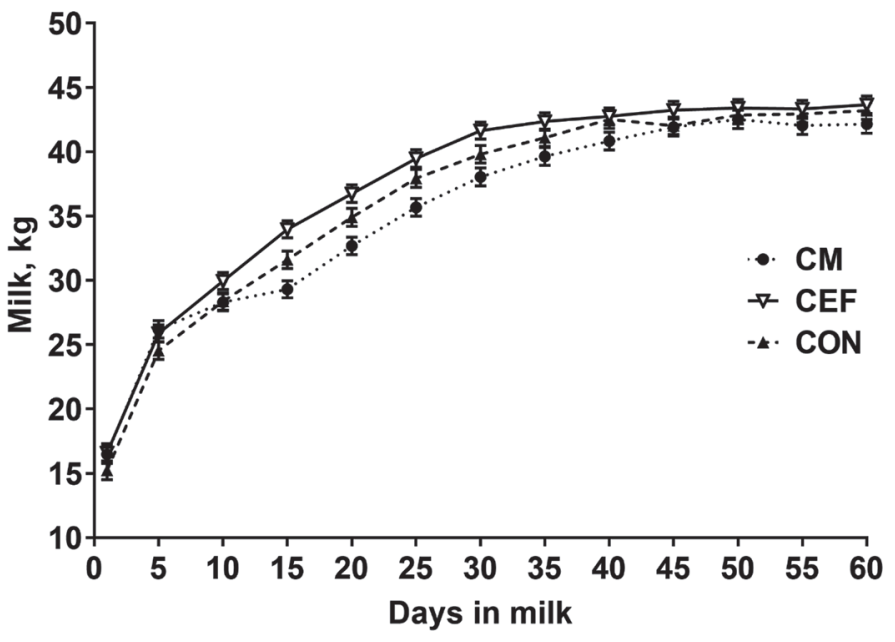

Figure 6. Least squares means $( \pm \mathrm{SE})$ of milk yield $(\mathrm{kg} / \mathrm{d})$ in the first 60 DIM according to treatment used. Daily milk yield was available from herds $\mathrm{A}$ and $\mathrm{C}$ only. Metritis was diagnosed in cows with a vaginal discharge that was fetid, thin, serous, or watery, reddishbrownish, and with or without pieces of necrotic tissue. Cows diagnosed with metritis were assigned randomly to receive CM $(\mathrm{n}=249)$, intrauterine infusion of $24 \mathrm{~g}$ of chitosan microparticles dissolved in 40 $\mathrm{mL}$ of sterile distilled water on d 0,2 , and 4 after diagnosis of metritis; CEF $(\mathrm{n}=247)$, a subcutaneous injection of $6.6 \mathrm{mg} / \mathrm{kg}$ ceftiofur crystalline-free acid (Excede, Zoetis, Parsippany, NJ) at the time of diagnosis of metritis and $3 \mathrm{~d}$ later; $\mathrm{CON}(\mathrm{n}=239)$, no treatment at the time of diagnosis. There was an effect of treatment $(P<0.01)$, time $(P<0.01)$, and an interaction between treatment and time $(P=$ 0.02 ) on milk yield within 60 DIM.

\section{Effect of Treatment on Monthly Milk Yield}

Treatment did not affect milk yield in the first 10 mo of lactation $(P=0.17$; Figure 7$)$, but an interaction between treatment and time $(P<0.01)$ showed that treatment had an effect on milk yield in the first 2 mo of lactation, as shown previously. The average milk yield in the first 10 mo of lactation was $36.8 \pm$ $0.5,37.9 \pm 0.5$, and $37.2 \pm 0.5 \mathrm{~kg} / \mathrm{d}$ for CM, CEF, and CON, respectively. For comparison, the NMET group had greater milk yield $(39.4 \pm 0.2 ; P<0.02) \mathrm{kg} / \mathrm{d}$ than all metritic groups (Supplemental Figure S5, https:// doi.org/10.3168/jds.2019-18028).

\section{Effect of Treatment on Pregnancy per Al at First Service}

Treatment had an effect $(P=0.05)$ on pregnancy per $\mathrm{AI}$ at first service, and pregnancy per AI was lesser $(P$ $=0.02)$ for $\mathrm{CM}$ than for CEF, but similar $(P=0.25)$ to that in $\mathrm{CON}(24.7 \pm 3.1$ vs. $35.8 \pm 3.1$ vs. $29.8 \pm$ $3.0 \%$, respectively) (Figure 8 ). There was no difference between CEF and CON $(P=0.18)$. For comparison, pregnancy per AI at first service was greater $(P<0.01)$ in NMET $(35.7 \pm 1.0 \%)$ than in $\mathrm{CM}$, tended to be greater $(P=0.09)$ in NMET than in $\mathrm{CON}$, but was 


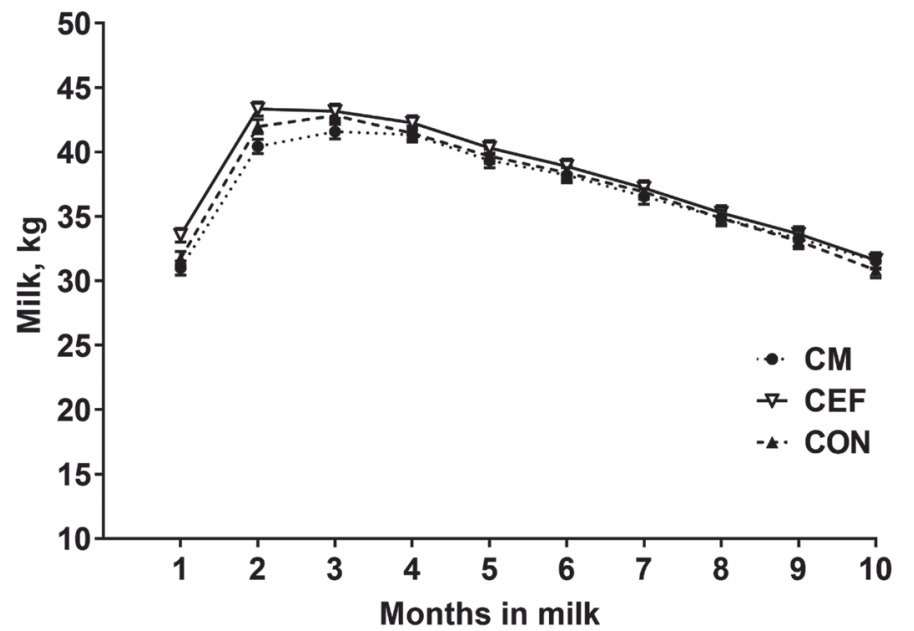

Figure 7 . Least squares means $( \pm \mathrm{SE})$ of milk yield $(\mathrm{kg} / \mathrm{d})$ in the first 10 mo according to treatment used. Metritis was diagnosed in cows with a vaginal discharge that was fetid, thin, serous, or watery, reddish-brownish, and with or without pieces of necrotic tissue. Cows diagnosed with metritis were assigned randomly to receive CM ( $\mathrm{n}=$ 276), intrauterine infusion of $24 \mathrm{~g}$ of chitosan microparticles dissolved in $40 \mathrm{~mL}$ of sterile distilled water on $\mathrm{d} 0,2$, and 4 after diagnosis of metritis; CEF ( $\mathrm{n}=275)$, a subcutaneous injection of $6.6 \mathrm{mg} / \mathrm{kg}$ ceftiofur crystalline-free acid (Excede, Zoetis, Parsippany, NJ) at the time of diagnosis of metritis and $3 \mathrm{~d}$ later; $\mathrm{CON}(\mathrm{n}=275)$, no treatment at the time of diagnosis. There was no effect of treatment $(P=0.17)$, but there was an effect of time $(P<0.01)$ and an interaction between treatment and time $(P<0.01)$ on monthly milk yield in the first 10 mo of lactation.

not different $(P=0.99)$ in NMET compared with CEF (Supplemental Figure S6, https://doi.org/10.3168/jds .2019-18028).

\section{Effect of Treatment on the Proportion of Cows Coded as DNB Within 300 DIM, Hazard of Culling, and Hazard of Pregnancy Within 300 DIM}

Treatment affected $(P<0.01)$ the proportion of cows coded as DNB within 300 DIM, and the proportion was greater for $\mathrm{CM}$ than $\mathrm{CEF}(18.5 \pm 2.5$ vs. $9.8 \pm$ $1.8 \% ; P<0.01)$, and tended to be greater for $\mathrm{CON}$ than $\mathrm{CEF}(14.6 \pm 2.2$ vs. $9.8 \pm 1.8 \% ; P=0.09)$. There was no difference between $\mathrm{CM}$ and $\mathrm{CON}(P=0.22)$. For comparison, the proportion of cows coded as DNB within 300 DIM was $10.4 \pm 0.7 \%$ in NMET, and was lesser $(P<0.04)$ than $\mathrm{CM}$ and $\mathrm{CON}$, but similar to CEF $(P=0.78)$.

Treatment affected $(P<0.01)$ the hazard of culling within 300 DIM, and the hazard of culling was greater for $\mathrm{CM}$ than $\mathrm{CEF}(\mathrm{HR}=1.83 ; 95 \%$ CI: $1.26-2.66$; $P$ $<0.01)$ and $\mathrm{CON}(\mathrm{HR}=1.68 ; 95 \% \mathrm{CI}: 1.17-2.42 ; P$ $<0.01$ ), but there was no difference between $\mathrm{CEF}$ and CON (HR $=0.92 ; 95 \%$ CI: 0.61-138; $P=0.68)$. Mean days to culling were 227,259 , and $257 \mathrm{~d}$ for CM, CEF, and CON, respectively (Figure 9). For comparison, mean days to culling was $275 \mathrm{~d}$ in NMET, and was lesser $(P<0.01)$ than all metritic groups (Supplemental Figure S7, https://doi.org/10.3168/jds.2019-18028).

Treatment affected $(P<0.01)$ the hazard of pregnancy within 300 DIM, and the hazard of pregnancy adjusted for culling or DNB was lesser for CM than CEF (HR $=0.62 ; 95 \%$ CI: $0.50-0.76 ; P<0.01)$, for $\mathrm{CM}$ than $\mathrm{CON}(\mathrm{HR}=0.77 ; 95 \% \mathrm{CI}: 0.62-0.95 ; P=$ $0.02)$, and for CON than $\mathrm{CEF}(\mathrm{HR}=0.80 ; 95 \% \mathrm{CI}$ : $0.65-0.99 ; P=0.04)$. Median days open were 246, 156, and $181 \mathrm{~d}$ for CM, CEF and CON, respectively (Figure 10). For comparison, median days open was $129 \mathrm{~d}$ in NMET, and was lesser $(P<0.01)$ than all metritic groups (Supplemental Figure S8, https://doi.org/10 $.3168 /$ jds.2019-18028).

\section{DISCUSSION}

The experiment was designed to evaluate different treatments for metritis in dairy cows. The main focus was to assess the efficacy of an intrauterine administration of CM. Overall, CM was ineffective at treating cows for metritis, and even tended to decrease cure risk than $\mathrm{CON}$ on $\mathrm{d} 6$, which indicates that $\mathrm{CM}$ delayed cure compared with CON. Cure risk for CM and CON were lower than CEF. Preliminary experiments from our group had indicated that CM could be a viable

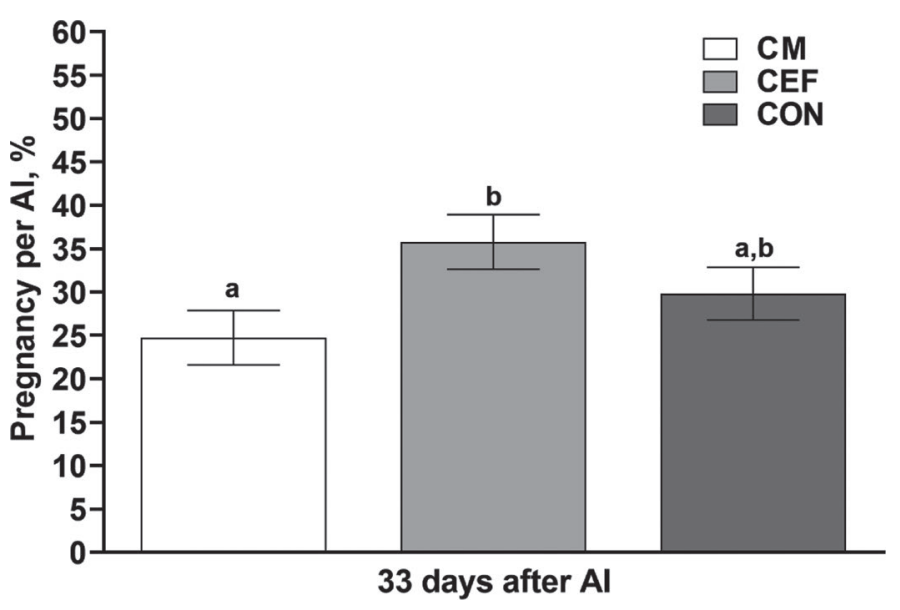

Figure 8. Proportion of cows pregnant at first AI according to treatment used. Metritis was diagnosed in cows with a vaginal discharge that was fetid, thin, serous, or watery, reddish-brownish, and with or without pieces of necrotic tissue. Cows diagnosed with metritis were assigned randomly to receive $\mathrm{CM}(\mathrm{n}=276)$, intrauterine infusion of $24 \mathrm{~g}$ of chitosan microparticles dissolved in $40 \mathrm{~mL}$ of sterile distilled water on $\mathrm{d} 0,2$, and 4 after diagnosis of metritis; CEF $(\mathrm{n}=275)$, a subcutaneous injection of $6.6 \mathrm{mg} / \mathrm{kg}$ ceftiofur crystalline-free acid (Excede, Zoetis, Parsippany, NJ) at the time of diagnosis of metritis and $3 \mathrm{~d}$ later; or CON $(\mathrm{n}=275)$, no treatment at the time of diagnosis. There was an effect of treatment $(P \leq 0.01)$ on pregnancy per $\mathrm{AI}$ at first service. Letters $(\mathrm{a}, \mathrm{b})$ indicate significant differences $(P \leq$ $0.05)$ among treatments after Tukey-Kramer adjustments. Error bars indicate SEM. 
treatment for metritis (Jeon et al., 2014, 2016). Chitosan microparticles were shown to have broad-spectrum antimicrobial activity in vitro (Jeon et al., 2014), and the same was expected in vivo. Indeed, Jeon et al. (2016) showed that CM was more effective than ceftiofur at reducing the relative abundance of Bacteroidetes, and was as effective as ceftiofur at reducing the relative abundance of Fusobacteria from d 0 to d 6 . Bacteroidetes and Fusobacteria are the major bacteria associated with metritis in dairy cows (Jeon et al., 2015; Galvão et al., 2019); therefore, these results indicated that CM was a promising alternative to traditional antibiotics. We also observed that CM administration from calving to 5 DIM reduced the incidence of metritis up to 7 DIM compared with untreated control cows, which further supported our hypothesis. However, microbiology work from this trial showed that CM hindered the progression of the uterine microbiome toward a healthy state compared with CON and CEF, and this was mostly due to greater relative abundance of Fusobacteria, particularly Fusobacterium in CM compared with CEF and CON on d 3 (Galvão et al., 2019). Furthermore, $\mathrm{CM}$ resulted in greater total bacterial counts than $\mathrm{CON}$ on d 6 and d 9 (K. N. Galvão, E. B. de Oliveira, F.

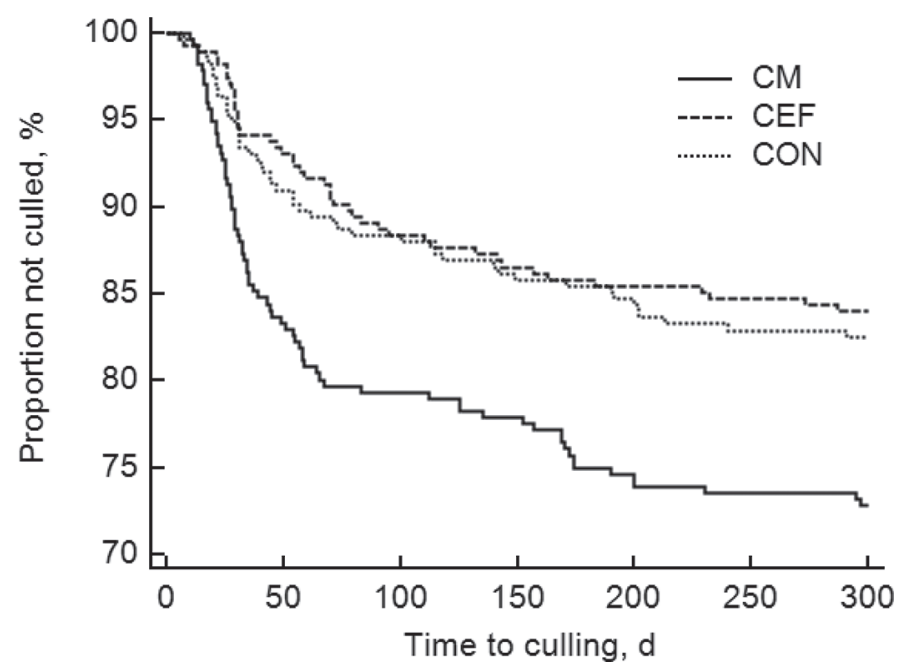

Figure 9. Kaplan-Meier survival curves for proportion of culling up to 300 DIM for cows diagnosed with metritis according to treatment used. Metritis was diagnosed in cows with a vaginal discharge that was fetid, thin, serous, or watery, reddish-brownish, and with or without pieces of necrotic tissue. Cows diagnosed with metritis were assigned randomly to receive $\mathrm{CM}(\mathrm{n}=276)$, intrauterine infusion of 24 $\mathrm{g}$ of chitosan microparticles dissolved in $40 \mathrm{~mL}$ of sterile distilled water on d 0, 2, and 4 after diagnosis of metritis; CEF $(\mathrm{n}=275)$, a subcutaneous injection of $6.6 \mathrm{mg} / \mathrm{kg}$ ceftiofur crystalline-free acid (Excede, Zoetis, Parsippany, NJ) at the time of diagnosis of metritis and $3 \mathrm{~d}$ later; CON $(\mathrm{n}=275)$, no treatment at the time of diagnosis. Overall effect of treatment from the Cox's proportional model: $P<0.01$. The hazard of culling was greater for CM than CEF $(P<0.01)$ and for $\mathrm{CM}$ than CON $(P<0.01)$, but there was no difference between $\mathrm{CEF}$ and $\operatorname{CON}(P=0.68)$.
Cunha, R. Daetz, and K. C. Jeong, unpublished). It is not clear why we have discrepancies from our previous studies, but could be a result of the limited sample size in our previous work (Jeon et al., 2016).

Treatment with CM resulted in greater culling than $\mathrm{CEF}$ or CON. Increased culling in CM cows is likely a result of an exacerbation of inflammation after $\mathrm{CM}$ infusion. Although CM did not result in increased concentrations of $\mathrm{Hp}$ or an increase in rectal temperature after infusion, it did increase the proportion of cows culled because of uterine related inflammatory conditions, such as metritis, pelvic inflammation, peritonitis, and mass in the pelvis. Treatment with CM also led to increased culling because of low milk yield. Exacerbation of inflammation may have shifted the metabolism even further toward insulin sensitivity, which is normally observed in cows undergoing an inflammatory process, likely causing a further decrease in milk yield because of further diversion of glucose away from the mammary gland (Bradford et al., 2015; Baumgard et al., 2017; Kvidera et al., 2017). The decrease in milk yield in cows treated with $\mathrm{CM}$ did not lead to a decrease in plasma concentration of NEFA and BHB, which is probably the result of a concomitant decrease in DMI associated with inflammation (Plata-Salamán et al., 1996;

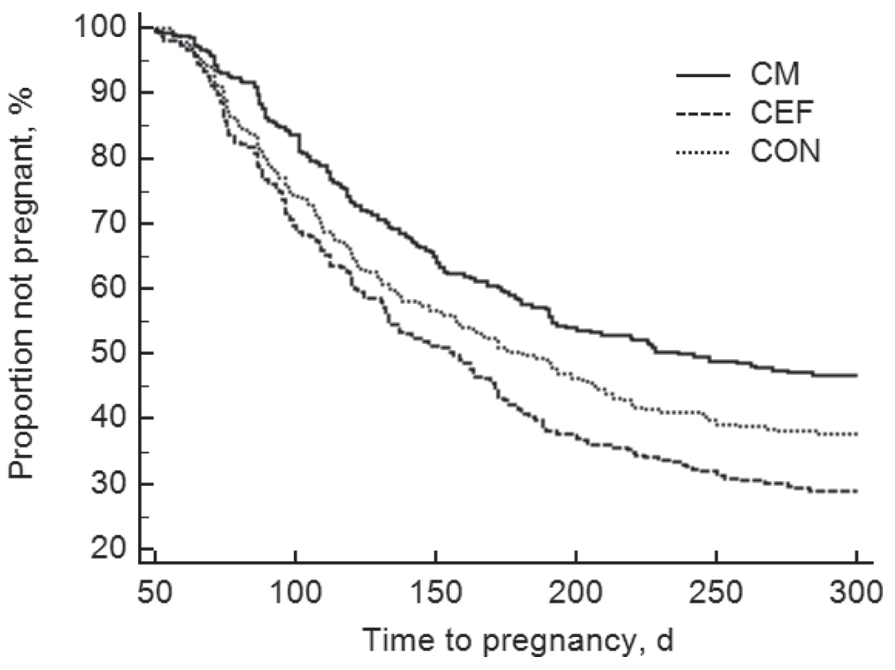

Figure 10. Kaplan-Meier survival curves for proportion of nonpregnant cows for cows diagnosed with metritis according to treatment used. Metritis was diagnosed in cows with a vaginal discharge that was fetid, thin, serous, or watery, reddish-brownish, and with or without pieces of necrotic tissue. Cows diagnosed with metritis were assigned randomly to receive CM $(\mathrm{n}=276)$, intrauterine infusion of $24 \mathrm{~g}$ of chitosan microparticles dissolved in $40 \mathrm{~mL}$ of sterile distilled water on $\mathrm{d}$ 0,2 , and 4 after diagnosis of metritis; CEF $(\mathrm{n}=275)$, a subcutaneous injection of $6.6 \mathrm{mg} / \mathrm{kg}$ ceftiofur crystalline-free acid (Excede, Zoetis, Parsippany, NJ) at the time of diagnosis of metritis and 3 d later; CON $(n=275)$, no treatment at the time of diagnosis. Overall effect of treatment from the Cox's proportional model: $P<0.001$. The hazard of pregnancy was lesser for CM than CEF $(P<0.01)$, for CM than CON $(P=0.02)$, and for CON than CEF $(P=0.04)$. 
Pérez-Báez et al., 2019). As expected, CM did not affect culling because of non-uterine-related conditions, such as mastitis, injury to teat/udder, lung abscess, fatty liver, digestive issues, trauma, or sudden death. It is not clear why $\mathrm{Hp}$ and rectal temperature were not increased in cows treated with $\mathrm{CM}$, but it is likely a result of a transient elevation of $\mathrm{Hp}(\sim 12 \mathrm{~h}$; Hiss et al., 2004) and rectal temperature ( $\sim 3 \mathrm{~h}$; Kvidera et al., 2017) after administration of an inflammatory agent. Therefore, it is possible that the degree of inflammation was not fully represented by rectal temperature or plasma concentrations of $\mathrm{Hp}$, but could be captured when cows were evaluated for culling reasons.

Chitosan is generally recognized as safe (GRAS) by the FDA, and is considered nontoxic, bioadhesive, biocompatible, and biodegradable. Nonetheless, Lanctôt et al. (2017) reported that infusion of chitosan hydrogel in the mammary gland of cows caused a sharp increase in somatic cells, indicating a rapid activation of an inflammatory response. Therefore, it is possible that CM had a similar effect when infused in the uterus. Another factor that may have contributed to exacerbated inflammation was the dose used. For the present experiment, the dose used was increased from $8 \mathrm{~g}$ to $24 \mathrm{~g}$ /infusion to achieve an estimated $0.6 \% \mathrm{CM}$ concentration in the uterine content, which was the concentration shown to be effective against $E$. coli ex vivo (Ma et al., 2015). In our previous experiment, using a dose of $8 \mathrm{~g} /$ infusion, we did not see any negative effect on uterine health or milk yield (Daetz et al., 2016). However, CM was used to try to prevent metritis (Daetz et al., 2016); therefore, administering $\mathrm{CM}$ to a damaged endometrium in cows with metritis might have a different inflammatory response than administering $\mathrm{CM}$ to a normal involuting endometrium.

The negative effects on fertility was another indication that $\mathrm{CM}$ was detrimental to uterine health. Cows in the CM treatment had increased proportion of cows coded as DNB, decreased pregnancy per AI at the first service, and decreased hazard of pregnancy by 300 DIM compared with $\mathrm{CEF}$ and CON. Again, it is likely that an exacerbated uterine inflammatory response in cows treated with $\mathrm{CM}$ led to more uterine tissue damage because of generation and release of reactive oxygen species, and the release of proteolytic enzymes (Lacy, 2006), which may have affected long-term fertility.

In addition to comparing cure risk, a secondary objective was to compare $\mathrm{CEF}$ and $\mathrm{CON}$ in regards to milk yield, culling, and fertility because these outcomes had not been evaluated during the approval trials for treatment of metritis with ceftiofur in the United States (Chenault et al., 2004; McLaughlin et al., 2012), and because of the general lack of studies evaluating production outcomes after antibiotic treatment of metritis
(Haimerl and Heuwieser, 2014; Haimerl et al., 2017). As previously reported, cows in CEF had increased risk of metritis cure than cows in CON (McLaughlin et al., 2012). Additionally, the proportions of cows cured of metritis in $\mathrm{CEF}$ and $\mathrm{CON}$ agreed with previous reports, which ranged from 75 to $78 \%$ for cows treated with ceftiofur and from 55 to $62 \%$ for untreated controls (Chenault et al., 2004; McLaughlin et al., 2012).

Recently, an experiment with grazing cows compared the use of ceftiofur crystalline-free acid for the treatment of metritis using a single subcutaneous administration compared with untreated controls, and reported that ceftiofur treatment did not affect 305 -d milk yield (Piccardi et al., 2016). Contrary to Piccardi et al. (2016), we observed that CEF increased milk yield, but the improvement in milk yield was only observed in the first 2 mo of lactation. The administration of a single dose of ceftiofur crystalline-free acid or the evaluation of 305-d milk yield, instead of daily or monthly, may have accounted for the discrepancy of results compared with Piccardi et al. (2016). Finally, milk yield was lower for CEF than NMET; therefore, although CEF resulted in an improvement in milk yield compared with CON, it did not completely reverse the negative effects of metritis on milk yield. It is also worth noting that the decrease in milk yield observed in CM compared with $\mathrm{CEF}$ and $\mathrm{CON}$, and for CEF and CON compared with NMET, is likely underestimated because of differences in culling, leading to follow-up bias. Because low milk yield is a major reason for culling, and because culled cows stop contributing milk yield data, it is reasonable to assume that differences in milk yield would be greater if milk yield data were available for all cows enrolled in the study. Interestingly, the proportion of cows culled in the first 60 DIM and the hazard of culling up to 300 DIM were not different between CEF and CON. This may be a result of escape therapy because although cows were left untreated when first diagnosed with metritis, cows could receive support therapy and escape therapy if their condition worsened. Indeed, we observed that the proportion of cows receiving support therapy was greater in CON than CEF. The proportion of cows receiving antibiotic escape therapy was not different between $\mathrm{CON}$ and $\mathrm{CEF}$, although it was numerically greater in CON. As expected CM had a greater proportion of cows receiving support therapy and antibiotic escape therapy than CEF and CON. Therefore, support therapy and escape therapy seemed to be sufficient to prevent increases in culling in CON, but not in CM.

Piccardi et al. (2016) also observed that ceftiofur treatment improved reproductive performance. In fact, ceftiofur treatment resulted in hazard of pregnancy similar to healthy cows. Herein we observed that CEF 
resulted in an increased hazard of pregnancy up to 300 DIM compared with CON, but the hazard of pregnancy was still lesser than NMET. It seems reasonable to expect that even an effective treatment of metritis would not completely reverse the damages caused by the inflammatory process in the uterus during metritis, such as change in the architecture of endometrial glands and scar tissue formation (McEntee, 1990). Most cases of uterine inflammation are associated with infections that happen during breeding or during the early postpartum (McEntee, 1990). Therefore, although CEF resulted in an improvement in reproductive performance compared with CON, it did not completely reverse the negative effects of metritis on fertility. Again, loss to follow-up would affect our ability to fully evaluate the negative effect of metritis and metritis treatment on long-term fertility, but herein, we used competing risk analysis to adjust for differences in loss to follow-up.

\section{CONCLUSIONS}

Intrauterine infusion of $24 \mathrm{~g}$ of $\mathrm{CM}$ dissolved in 40 $\mathrm{mL}$ of sterile distilled water every other day (for a total of 3 treatments) as therapy for metritis did not improve cure rate, but was detrimental to milk yield, culling, and fertility compared with CON. Cows in the CEF treatment had an increased cure of metritis, milk yield, and fertility compared with $\mathrm{CM}$ and $\mathrm{CON}$; however, culling was greater, and milk yield and fertility were lesser than NMET. Treatment did not affect plasma Hp, NEFA, or BHB concentrations. The results from this experiment indicate that $\mathrm{CM}$ used as described in this study is ineffective in the treatment of metritis, and is detrimental to milk production, survival, and fertility in dairy cows. In contrast, CEF was confirmed to be an effective treatment of metritis, and was shown to increase milk yield and fertility when compared with CON. Finally, the negative effects of metritis on milk yield, culling, and fertility could not be completely reversed by CEF treatment.

\section{ACKNOWLEDGMENTS}

The data presented herein was generated with the support of a grant from the USDA-NIFA-AFRI program (Accession Number: 1008863). We thank the owner, Don Bennink, and the staff of North Florida Holsteins, the general manager, Ed Silba, and the staff of American Dairy Co., and the general manager, Todd Pritchard, and the staff of the University of Florida Dairy Unit for allowing us to conduct this trial in their dairies. Also, we express our gratitude to Alyssa Walker, Andre Felipe Cavalli, Alex Aguilar, Bruno Garcia, Elizabeth Waskover, Felipe Garcia, Gustavo
Soeiro, Holly Haywood, Maria Noguera, Stephanie Clime, Stephanie Mathews, Vinicius Junior Lima, and Victoria Rocha (University of Florida, Gainesville) for their invaluable assistance during the experiment and with data collection. The authors have not stated any conflicts of interest.

\section{REFERENCES}

Baldrick, P. 2010. The safety of chitosan as a pharmaceutical excipient. Regul. Toxicol. Pharmacol. 56:290-299. https://doi.org/10 .1016/j.yrtph.2009.09.015.

Baumgard, L. H., R. J. Collier, and D. E. Bauman. 2017. A 100 year review: Regulation of nutrient partitioning to support lactation. J. Dairy Sci. 100:10353-10366. https://doi.org/10.3168/jds.2017 -13242 .

Bell, M. J., and D. J. Roberts. 2007. The impact of uterine infection on a dairy cow's performance. Theriogenology 68:1074-1079. https:// doi.org/10.1016/j.theriogenology.2007.08.010.

Benzaquen, M. E., C. A. Risco, L. F. Archbald, P. Melendez, M.-J. Thatcher, and W. W. Thatcher. 2007. Rectal temperature, calving-related factors, and the incidence of puerperal metritis in postpartum dairy cows. J. Dairy Sci. 90:2804-2814. https://doi.org/10 $.3168 /$ jds.2006-482.

Bicalho, R. C., V. S. Machado, M. L. S. Bicalho, R. O. Gilbert, A. G. V. Teixeira, L. S. Caixeta, and R. V. Pereira. 2010. Molecular and epidemiological characterization of bovine intrauterine Escherichia coli. J. Dairy Sci. 93:5818-5830. https://doi.org/10.3168/jds.2010 -3550 .

Bradford, B. J., K. Yuan, J. K. Farney, L. K. Mamedova, and A. J. Carpenter. 2015. Invited review: Inflammation during the transition to lactation: New adventures with an old flame. J. Dairy Sci. 98:6631-6650. https://doi.org/10.3168/jds.2015-9683.

Chenault, J. R., J. F. McAllister, S. T. Chester, K. J. Dame, F. M. Kausche, and E. J. Robb .2004. Efficacy of ceftiofur hydrochloride sterile suspension administered parenterally for the treatment of acute postpartum metritis in dairy cows. J. Am. Vet. Med. Assoc. 224:1634-1639. https://doi.org/10.2460/javma.2004.224.1634.

Cooke, R. F., and J. D. Arthington. 2013. Concentrations of haptoglobin in bovine plasma determined by elisa or a colorimetric method based on peroxidase activity. J. Anim. Physiol. Anim. Nutr. (Berl.) 97:531-536. https://doi.org/10.1111/j.1439-0396.2012.01298.x.

Daetz, R., F. Cunha, J. H. Bittar, C. A. Risco, F. Magalhaes, Y. Maeda, J. E. P. Santos, K. C. Jeong, R. F. Cooke, and K. N. Galvão. 2016. Clinical response after chitosan microparticle administration and preliminary assessment of efficacy in preventing metritis in lactating dairy cows. J. Dairy Sci. 99:8946-8955. https://doi.org/ 10.3168/jds.2016-11400.

De Briyne, N., J. Atkinson, S. P. Borriello, and L. Pokludová .2014. Antibiotics used most commonly to treat animals in Europe. Vet. Rec. 175:325. https://doi.org/10.1136/vr.102462.

Dubuc, J., T. F. Duffield, K. E. Leslie, J. S. Walton, and S. J. LeBlanc. 2010. Risk factors for postpartum uterine diseases in dairy cows. J. Dairy Sci. 93:5764-5771. https://doi.org/10.3168/jds.2010-3429.

Erb, H. N., and S. W. Martin. 1980. Interrelationships between production and reproductive diseases in Holstein cows. Age and seasonal patterns. J. Dairy Sci. 63:1918-1924. https://doi.org/10 .3168/jds.S0022-0302(80)83159-6.

Ferguson, J. D., D. T. Galligan, and N. Thomsen. 1994. Principal descriptors of body condition score in Holstein cows. J. Dairy Sci. 77:2695-2703.

Fine, J. P., and R. J. Gray. 1999. A proportional hazards model for the subdistribution of a competing risk. J. Am. Stat. Assoc. 94:496509. https://doi.org/10.1080/01621459.1999.10474144.

Galvão, K. N., E. de Oliveira, F. Cunha, R. Daetz, R. Chebel, C. Risco, J. Santos, K. C. Jeong, R. C. Bicalho, and C. GonzalezMoreno. 2019. Effect of chitosan microparticles on the uterine microbiome of dairy cows with metritis. J. Dairy Sci. 102(Suppl. 1):286. (Abstr.) 
Gier, H. T., and G. B. Marion. 1968. Uterus of the cow after parturition: Involutional changes. Am. J. Vet. Res. 29:83-96.

Giuliodori, M. J., R. P. Magnasco, D. Becu-Villalobos, I. Lacau-Mengido, C. A. Risco, and R. de la Sota. 2013. Metritis in dairy cows: Risk factors and reproductive performance. J. Dairy Sci. 96:36213631. https://doi.org/10.3168/jds.2012-5922.

Guo, C., and Y. So. 2018. Cause-specific analysis of competing risks using the PHREG procedure. Paper SAS2159-2018 in Proceedings of the SAS Global Forum, Denver CO. SAS Institute Inc., Cary, NC.

Haimerl, P., S. Arlt, S. Borchardt, and W. Heuwieser. 2017. Antibiotic treatment of metritis in dairy cows-A meta-analysis. J. Dairy Sci. 100:3783-3795. https://doi.org/10.3168/jds.2016-11834.

Haimerl, P., and W. Heuwieser. 2014. Invited review: Antibiotic treatment of metritis in dairy cows: A systematic approach. J. Dairy Sci. 97:6649-6661. https://doi.org/10.3168/jds.2014-8462.

Hiss, S., M. Mielenz, R. M. Bruckmaier, and H. Sauerwein. 2004. Haptoglobin concentrations in blood and milk after endotoxin challenge and quantification of mammary $\mathrm{Hp}$ mRNA expression. J. Dairy Sci. 87:3778-3784. https://doi.org/10.3168/jds.S0022 -0302(04)73516-X.

Jeon, S. J., Z. Ma, M. Kang, K. N. Galvão, and K. C. Jeong. 2016. Application of chitosan microparticles for treatment of metritis and in vivo evaluation of broad spectrum antimicrobial activity in cow uteri. Biomaterials 110:71-80. https://doi.org/10.1016/j .biomaterials.2016.09.016.

Jeon, S. J., M. Oh, W. S. Yeo, K. N. Galvão, and K. C. Jeong. 2014. Underlying mechanism of antimicrobial activity of chitosan microparticles and implications for the treatment of infectious diseases. PLoS One 9:e92723. https://doi.org/10.1371/journal.pone .0092723 .

Jeon, S. J., A. Vieira-Neto, M. Gobikrushanth, R. Daetz, R. D. Mingoti, A. C. B. Parize, S. L. de Freitas, A. N. L. da Costa, R. C. Bicalho, S. Lima, K. C. Jeong, and K. N. Galvão. 2015. Uterine microbiota progression from calving until establishment of metritis in dairy cows. Appl. Environ. Microbiol. 81:6324-6332. https://doi .org/10.1128/AEM.01753-15.

Juchem, S. O., R. L. Cerri, M. Villaseñor, K. N. Galvão, R. G. Bruno, H. M. Rutigliano, E. J. DePeters, F. T. Silvestre, W. W. Thatcher, and J. E. Santos. 2010. Supplementation with calcium salts of linoleic and trans-octadecenoic acids improves fertility of lactating dairy cows. Reprod. Domest. Anim. 45:55-62. https://doi.org/10 .1111/j.1439-0531.2008.01237.x.

Kossaibati, M. A., and R. J. Esslemont. 1997. The costs of production diseases in dairy herds in England. Vet. J. 154:41-51. https://doi .org/10.1016/S1090-0233(05)80007-3.

Kvidera, S. K., E. A. Horst, M. Abuajamieh, E. J. Mayorga, M. V. Sanz Fernandez, and L. H. Baumgard. 2017. Glucose requirements of an activated immune system in lactating Holstein cows. J. Dairy Sci. 100:2360-2374. https://doi.org/10.3168/jds.2016-12001.

Lacy, P. 2006. Mechanisms of degranulation in neutrophils. Allergy Asthma Clin. Immunol. 2:98-108. https://doi.org/10.1186/1710 -1492-2-3-98.

Lanctôt, S., P. Fustier, A. R. Taherian, B. Bisakowski, X. Zhao, and P. Lacasse. 2017. Effect of intramammary infusion of chitosan hydrogels at drying-off on bovine mammary gland involution. J. Dairy Sci. 100:2269-2281. https://doi.org/10.3168/jds.2016-12087.

LeBlanc, S. J., T. F. Duffield, K. E. Leslie, K. G. Bateman, G. P. Keefe, J. S. Walton, and W. H. Johnson. 2002. Defining and diagnosing postpartum clinical endometritis and its impact on reproductive performance in dairy cows. J. Dairy Sci. 85:2223-2236. https://doi.org/10.3168/jds.S0022-0302(02)74302-6.

Ma, Z., L. Teng, D. Kim, K. N. Galvão, C. D. Nelson, A. T. Adesogan, and K. C. Jeong. 2015. Evaluation of antimicrobial activity of chitosan microparticles in different matrices from dairy cows. J. Dairy Sci. 98(Suppl. 1):324. (Abstr.)

Markusfeld, O. 1987. Periparturient traits in seven high dairy herds. Incidence rates, association with parity, and interrelationships among traits. J. Dairy Sci. 70:158-166. https://doi.org/10.3168/ jds.S0022-0302(87)79990-1.
Mateus, L., L. Lopes da Costa, F. Bernardo, and J. Robalo Silva. 2002 Influence of puerperal uterine infection on uterine involution and postpartum ovarian activity in dairy cows. Reprod. Domest. Anim. 37:31-35. https://doi.org/10.1046/j.1439-0531.2002.00317.x.

McDougall, S., R. Macaulay, and C. Compton. 2007. Association between endometritis diagnosis using a novel intravaginal device and reproductive performance in dairy cattle. Anim. Reprod. Sci. 99:923. https://doi.org/10.1016/j.anireprosci.2006.03.017.

McEntee, K. 1990. Reproductive Pathology of Domestic Animals. Academic Press, Inc. San Diego, CA.

McLaughlin, C. L., E. Stanisiewski, M. J. Lucas, C. P. Cornell, J. Watkins, L. Bryson, J. K. S. Tena, J. Hallberg, and J. R. Chenault. 2012. Evaluation of two doses of ceftiofur crystalline free acid sterile suspension for treatment of metritis in lactating dairy cows. J. Dairy Sci. 95:4363-4371. https://doi.org/10.3168/jds.2011-5111.

NRC. 2001. Nutrient Requirements of Dairy Cattle. 7th ed. National Academy Press, Washington, DC.

Pérez-Báez, J., C. A. Risco, R. C. Chebel, G. C. Gomes, L. F. Greco, S. Tao, I. M. Thompson, B. C. do Amaral, M. G. Zenobi, N. Martinez, C. R. Staples, G. E. Dahl, J. A. Hernández, J. E. P. Santos, and K. N. Galvão. 2019. Association of dry matter intake and energy balance prepartum and postpartum with health disorders postpartum: Part I. Calving disorders and metritis. J. Dairy Sci. 102:9138-9150. https://doi.org/10.3168/jds.2018-15878.

Piccardi, M., G. Romero, G. Veneranda, E. Castello, D. Romero, M. Balzarini, and G. A. Bo. 2016. Effect of puerperal metritis on reproductive and productive performance in dairy cows in $\mathrm{Ar}$ gentina. Theriogenology 85:887-893. https://doi.org/10.1016/j theriogenology.2015.10.038.

Plata-Salamán, C. R., G. Sonti, J. P. Borkoski, C. D. Wilson, and J. M.H. Ffrench-Mullen. 1996. Anorexia induced by chronic central administration of cytokines at estimated pathophysiological concentrations. Physiol. Behav. 60:867-875.https://doi.org/10.1016/ 0031-9384(96)00148-5.

Pleticha, S., M. Drillich, and W. Heuwieser. 2009. Evaluation of the Metricheck device and the gloved hand for the diagnosis of clinical endometritis in dairy cows. J. Dairy Sci. 92:5429-5435. https://doi .org/10.3168/jds.2009-2117.

Sheldon, I. M., J. Cronin, L. Goetze, G. Donofrio, and H. J. Schuberth. 2009. Defining postpartum uterine disease and the mechanisms of infection and immunity in the female reproductive tract in cattle. Biol. Reprod. 81:1025-1032. https://doi.org/10.1095/biolreprod .109.077370.

Sheldon, I. M., and H. Dobson. 2004. Postpartum uterine health in cattle. Anim. Reprod. Sci. 82-83:295-306. https://doi.org/10 .1016/j.anireprosci.2004.04.006.

Stojkov, J., M. A. G. Von Keyserlingk, J. N. Marchant-Forde, and D. M. Weary. 2015. Assessment of visceral pain associated with metritis in dairy cows. J. Dairy Sci. 98:5352-5361. https://doi.org/10 .3168/jds.2014-9296.

Vieira-Neto, A., F. S. Lima, J. E. P. Santos, R. D. Mingoti, G. S. Vasconcellos, C. A. Risco, and K. N. Galvao. 2016. Vulvovaginal laceration as a risk factor for uterine disease in postpartum dairy cows. J. Dairy Sci. 99:4629-4637.

\section{ORCIDS}

E. B. de Oliveira @ https://orcid.org/0000-0002-0434-8501

F. Cunha (1) https://orcid.org/0000-0002-8947-7686

C. C. Figueiredo ( https://orcid.org/0000-0003-0890-0743

R. C. Chebel @ https://orcid.org/0000-0002-9700-8089

J. E. Santos @ https://orcid.org/0000-0003-3403-1465

K. C. Jeong (๑) https://orcid.org/0000-0003-4337-0426

V. S. Machado @ https://orcid.org/0000-0003-1513-8216

K. N. Galvão @ https://orcid.org/0000-0002-6683-4476 